\title{
Occupational Hearing Loss from Non-Gaussian Noise
}

\author{
Alice H. Suter, Ph.D. ${ }^{1}$
}

\section{ABSTRACT}

Noise levels are truly continuous in relatively few occupations, with some degree of intermittency the most common condition. The sound levels of intermittent noise are often referred to as non-Gaussian in that they are not normally distributed in the time domain. In some conditions, intermittent noise affects the ear differently from continuous noise, and it is this assumption that underlies the selection of the $5-\mathrm{dB}$ exchange rate (ER). The scientific and professional communities have debated this assumption over recent decades. This monograph explores the effect of non-Gaussian noise on the auditory system. It begins by summarizing an earlier report by the same author concentrating on the subject of the ER. The conclusions of the earlier report supported the more conservative 3- $\mathrm{dB}$ ER with possible adjustments to the permissible exposure limit for certain working conditions. The current document has expanded on the earlier report in light of the relevant research accomplished in the intervening decades. Although some of the animal research has supported the mitigating effect of intermittency, a closer look at many of these studies reveals certain weaknesses, along with the fact that these noise exposures were not usually representative of the conditions under which people actually work. The more recent animal research on complex noise shows that intermittencies do not protect the cochlea and that many of the previous assumptions about the ameliorative effect of intermittencies are no longer valid, lending further support to the 3-dB ER. The neurologic effects of noise on hearing have gained increasing attention in recent years because of improvements in microscopy and immunostaining techniques. Animal experiments showing damage to auditory synapses from noise exposures previously considered harmless may signify the need for a more conservative approach to the assessment of noise-induced hearing loss and consequently the practice of hearing conservation programs.

\footnotetext{
${ }^{1}$ Alice Suter and Associates, Portland, Oregon.

Semin Hear 2017;38:225-262. Copyright (C) 2017 by Address for correspondence: Alice H. Suter, Ph.D., 1106 NE Tillamook St., Portland, OR 97212 (e-mail: ahsuter@comcast.net).

Occupational Hearing Loss from Non-Gaussian Noise; Guest Editor, Mark R. Stephenson, Ph.D. Thieme Medical Publishers, Inc., 333 Seventh Avenue, New York, NY 10001, USA. Tel: +1(212) 584-4662. DOI: https://doi.org/10.1055/s-0037-1603726. ISSN 0734-0451.
} 
KEYWORDS: Noise, non-Gaussian noise, hearing loss, occupational hearing loss

\section{OVERVIEW}

Learning Outcomes: As a result of this activity, the participant will be able to list recent evidence that supports a re-examination of the auditory damage-risk criteria for various noise exposure environments.

Noise exposure has been a serious concern since the beginning of industrialization, and the harmful effects on hearing have been well known for nearly that entire time. Millions of American workers have suffered hearing impairments as a result. In 1981, the U.S. Environmental Protection Agency (EPA) estimated approximately nine million American workers were exposed to A-weighted occupational noise levels of $85 \mathrm{~dB}$ (dBA) and above. ${ }^{1}$ Over five million of these people worked in manufacturing and utilities, nearly one million in the military, and one-half million in construction. Since then, these numbers may have decreased somewhat due to automation and globalization, but hearing loss from occupational noise is still a widespread and serious problem.

More recent demographic data on worker noise exposure would certainly be useful.

It also would be helpful to know more about the acoustical characteristics of noise in various work environments. Although there is a considerable amount of information about the acoustics of individual machines, there is relatively little data about the overall noise environments of employees in typical workplaces and in the nation as a whole.

In this report, the temporal characteristics of occupational noise are of primary interest. Certain noise sources tend to produce an environment where the noise level remains constant and stable over time. Examples would be textile weaving and spinning machines, boilers in power plants, and ventilation systems. However, noise environments that vary considerably in the temporal domain are quite common in many workplaces. These environments would include everything from the generalized din of metalworking shops, to the on-and-off volley from impact wrenches in a tire shop, to the impulses occurring at a shooting range. Noise levels may change relatively slowly, as in warehouses or some facto- ries like poultry processing plants, whereas bursts of noise interspersed with periods of quiet would characterize the work environments of firefighters, ramp workers at airports, or forestry workers using chain saws. Perhaps the most typical worker exposure would be for people who spend much of their days moving from noise source to noise source, even though the individual environments might be stable. Typical of this job would be the plant maintenance worker. All of these noise environments would be considered intermittent.

The term intermittent is often used broadly to cover a range of acoustic environments characterized by temporal variations in the noise signal. The idea that intermittent noise affects the ear differently from steady-state noise is not new, with research in this area dating back to the 1960s. However, the effects of intermittent noise have received increasing attention over recent years, resulting in a large number of studies.

Various researchers maintain that intermittent noise is less damaging, equally damaging, or, in some cases, more damaging than continuous noise of equivalent energy. Differences in temporal pattern appear to cause differences in the amount and type of damage to the hearing mechanism. Because the temporal distribution of these noise environments is not normal or Gaussian, it may be referred to as non-Gaussian noise or complex noise. Of particular interest lately is the effect of impulse or impact noise superimposed on a background of continuous noise. These subjects will be explored in greater detail in later sections of this report.

As scientific attention has focused on the auditory effects of various types of intermittencies, researchers have asked salient questions about the exchange rate (ER) between noise exposure level and duration. Is the equal energy rule (3-dB ER) incorporated in the International Organization for Standardization (ISO) standard ISO 1999 
overprotective for intermittent exposures? Under what circumstances are intermittent exposures less damaging or possibly more damaging than continuous ones? To what extent does the inclusion of impulse and impact stimuli in otherwise continuous exposures increase the hazard? Which $\mathrm{ER}$, the $5-\mathrm{dB}$ rule used by the Occupational Safety and Health Administration (OSHA) or the $3-\mathrm{dB}$ rule used by several other agencies and governments, is justified by scientific data?

These kinds of issues were the subject of a previous report submitted to the National Institute for Occupational Safety and Health (NIOSH) in 1992 entitled "The Relationship of the Exchange Rate to Noise-Induced Hearing Loss." ${ }^{2}$ The purpose of the current report is to summarize and update the previous report, but because of the amount and relevance of research accomplished between then and the present, this report has been broadened to include two important areas: (1) the use of the kurtosis metric to assess the effects of non-Gaussian noise environments on hearing in both animals and humans, and (2) investigations in animals involving auditory synaptopathy, the destruction of synaptic connections between hair cells and auditory nerve terminals. Research in both of these areas involves a re-evaluation of the damaging effects of noise on the auditory system, signifying the need for a more conservative approach to the assessment of noise-induced hearing damage. This approach is therefore necessary for the development of damage-risk criteria, of which the issue of the ER is an integral part.

The ER is the relationship between allowable noise exposure level and the halving or doubling of duration for the purposes of standards, regulations, or criteria development. It also has been referred to as the time-intensity trading relation, or the doubling rate. The principal ERs used in the United States and elsewhere in the world are the 3-dB ER, also known as the equal-energy rule, and the 5-dB ER, or OSHA method. Deliberations concerning the method that best predicts hearing loss have centered around the role of intermittency and the extent to which temporal variations in the noise signal may allow the ear to recover and ameliorate the adverse effects of noise. In recent years, controversy has arisen over whether any energy method is sufficiently conservative to assess the hazard of background noise containing short-duration, high-level components, such as the impact noise found in many types of manufacturing operations.

The progression in research on the effects of noise over the decades between $\sim 1960$ and the present may be seen as a continuum of complexity ranging from the noise exposure and hearing threshold levels (HTLs) of workers measured with rudimentary sound level meters and audiometers, to laboratory studies of temporary threshold shift (TTS) and asymptotic threshold shift (ATS) in humans and animals, then permanent threshold shift (PTS), and cochlear hair cell loss in animals. These studies were followed by more complex studies of hair cell damage along the basilar membrane. More recently, researchers have concentrated on neurologic damage and specifically synaptopathy in animals exhibiting normal audiometric thresholds and even normal cell counts of outer hair cells (OHCs) and inner hair cells (IHCs).

The findings of these more recent studies argue for a more conservative approach to the development of damage-risk criteria. This approach includes issues pertaining to the recommended exposure limit (REL), noise measurement methodologies, and the treatment of impulse noise. It also includes a re-examination of the ER and any adjustments to the ER for specific occupational noise conditions.

In this report, the ER may be seen as a unifying concept in that it is affected by the findings from many types of studies relating the temporal aspects of noise to damage in the auditory system. These temporal aspects include such descriptors as fluctuating, time-varying, intermittent, interrupted, and impulsive noise, all of which are simply variants of non-Gaussian noise.

\section{ATTEMPTS TO DEFINE NON- GAUSSIAN NOISE}

Learning Outcomes: As a result of this activity, the participant will be able to compare and contrast Gaussian versus non-Gaussian noise, continuous versus intermittent noise, and impulse versus impact noise.

Over the years, various methods of defining non-Gaussian noise in terms of intermittent 
and varying noise have been put forward by government agencies, professionals, and consensus groups. Fig. 1 gives a graphic example of short-interval and long-interval segments in both intermittent and varying noise environments. ${ }^{3}$ Groups engaged in the development of criteria for noise exposure have suggested definitions that address either level or temporal parameters of noise, and sometimes both, many of which have been quite complicated.

Some examples of these early definitions date from the 1960s and 1970s. The National Academy of Sciences Committee on Hearing and Bioacoustics (CHABA) described intermittent noise as individual noise bursts that do not exceed 2 minutes in duration and where there is alternation between noise bursts and noise levels below the 8-hour allowable level for a particular band of noise or pure tone. ${ }^{4}$ In noise environments defined as fluctuating or varying, levels never drop below the specified 8-hour level. Different allowable levels were given for different combinations of frequencies and durations. The Environmental Protection Agency's "Levels Document" specified interrupted noise as levels that fall below $65 \mathrm{dBA}$ for $10 \%$ of each hour. ${ }^{5}$ Both of these definitions of intermittent noise assume a certain level of "effective quiet" as an important factor. Effective quiet may be considered the highest level of noise that will not interfere with recovery from TTS.

The noise environment becomes more complicated when it includes impulse noise (typically from weapons) or impact noise, which is characteristic of many manufacturing processes. The classic impulse or Friedlander wave is generated by a rapid expansion of gas from a chemical explosion, as with a gunshot, or a compressed air burst, as with a pneumatic tool. Fig. 2, from Flamme and Murphy, ${ }^{6}$ shows variations of the classic impulse pressure wave characterized by

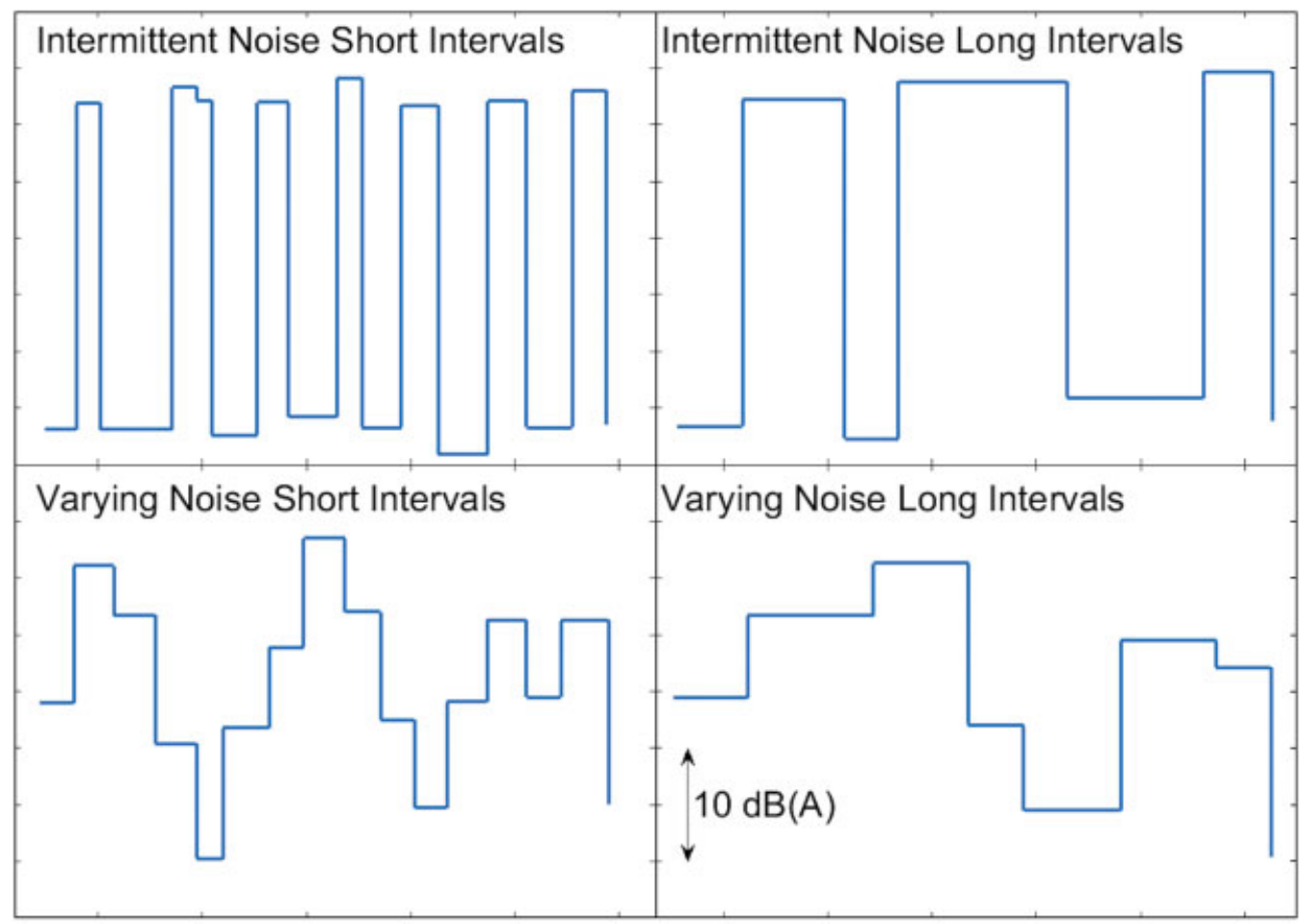

Figure 1 Illustration of short-interval and long-interval segments in intermittent and varying noise environments (from Passchier-Vermeer ${ }^{3}$ ). 


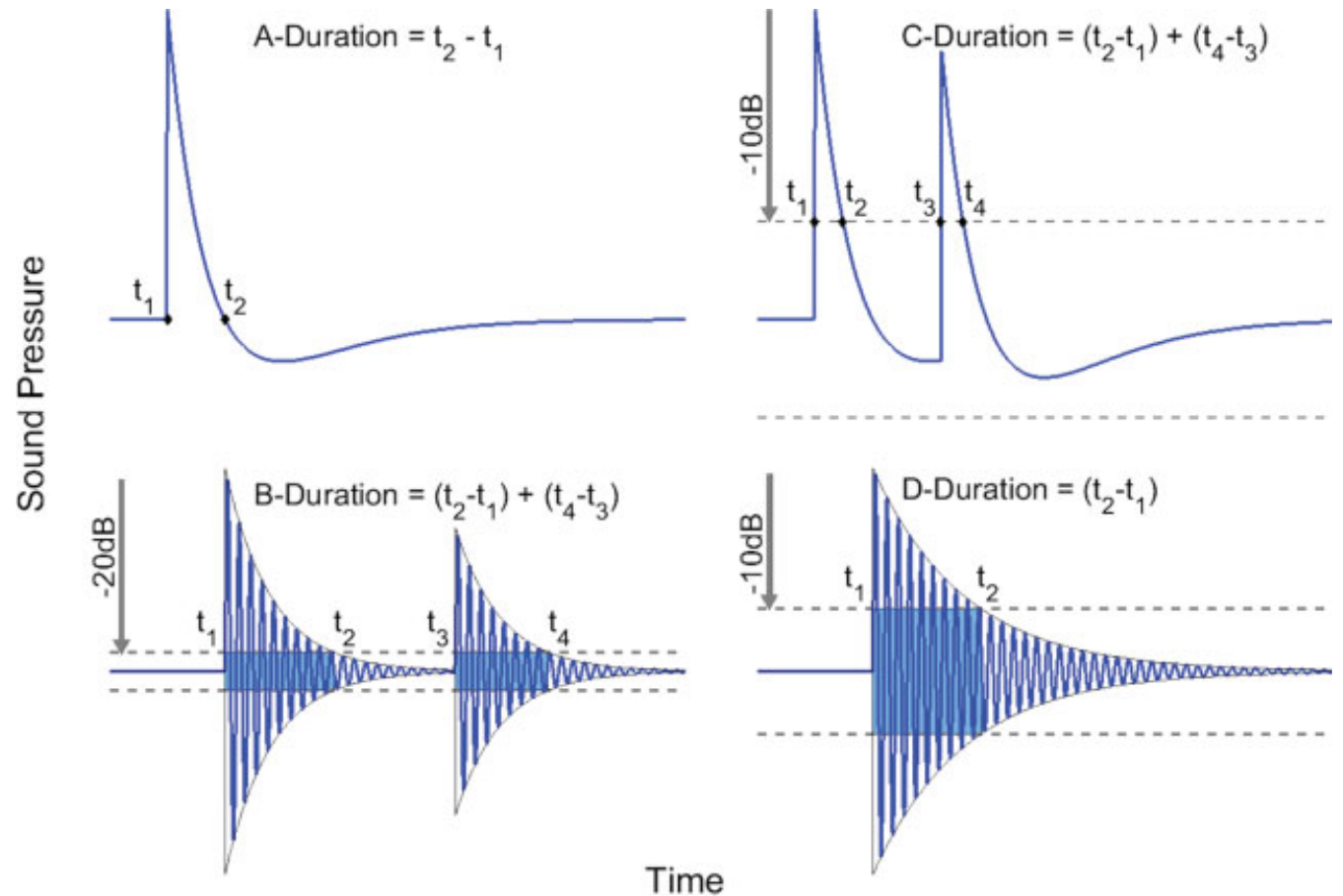

Figure 2 Illustration of impulse sound waves according to duration parameters (from Flamme and Murphy; ${ }^{6}$ reprinted with permission).

different duration parameters, with $\mathrm{A}, \mathrm{B}, \mathrm{C}$, and $\mathrm{D}$ durations used in different damagerisk criteria for impulse noise. The impulse waveform can be changed and prolonged considerably when measured indoors because of reflective surfaces, as in Fig. 3 from Hamernik and Hsueh. ${ }^{7}$

Impact noise is generated by the collision of two or more solid objects, as in metal stamping, hammering, riveting, and forging. Impact peak levels tend to be somewhat lower than impulses. Impulse peak levels generally exceed $140 \mathrm{~dB}$ whereas impact peak levels are usually lower than $140 \mathrm{~dB},{ }^{7}$ but the durations of impacts are often longer because of differences in the sound sources themselves and also due to the reverberation and reflection characteristics of indoor environments. Both impulses and impacts may be superimposed on a background of continuous or varying noise, which increases the hazard to hearing, ${ }^{8-11}$ as will be discussed in subsequent paragraphs.

\section{SUMMARY OF THE PREVIOUS REPORT TO THE NATIONAL INSTITUTE FOR OCCUPATIONAL SAFETY AND HEALTH ON THE EXCHANGE RATE (1992)}

Learning Outcomes: As a result of this activity, the participant will be able to list two important findings from the previous NIOSH report.

\section{Development of Criteria and Standards}

Early criteria and standards include those developed by the U.S. Air Force, the International Organization for Standardization (ISO) as ISO 1999 in several iterations (e.g., ISO $^{12,13}$ ), CHABA and various modifications to its criteria, and the "Intersociety Committee," all between the years 1955 and 1970. These early criteria were based primarily on studies of TTS in humans, usually measured 2 minutes after cessation of exposure $\left(\mathrm{TTS}_{2}\right)$. The expected outcomes were expressed in terms of decibels 


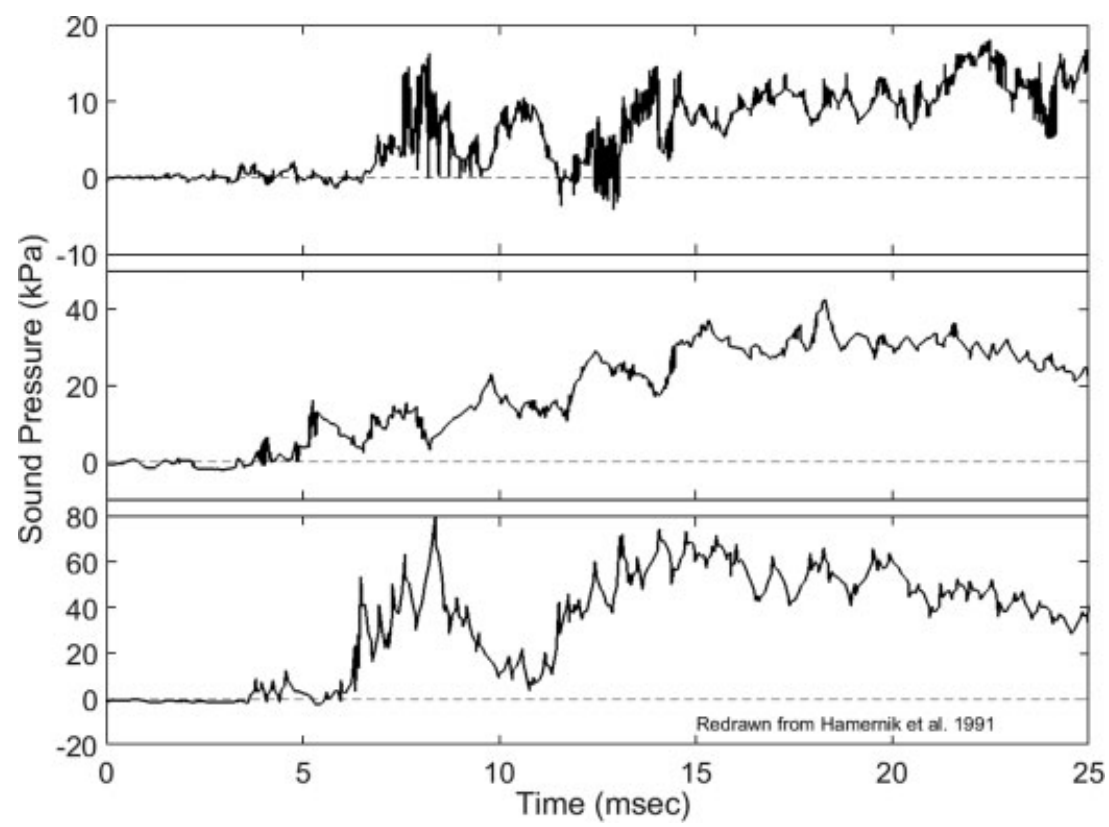

Figure 3 Examples of three different impulses recorded within a hard-walled enclosure showing peak sound pressure level as a function of time in milliseconds. Durations of these kinds of impulses are more difficult to establish due to alterations of the waveform caused by reflected components (after Hamernik and Hsueh, ${ }^{7}$ with permission).

of $\mathrm{TTS}_{2}$ for various audiometric frequencies, such as 1,2 , and $3 \mathrm{kHz}$. Fig. 4 gives one example of these efforts, showing allowable exposure cycles for noncontinuous noise contingent upon noise level, on-time, and off-time. ${ }^{14}$

The CHABA criteria were based on the following postulates: (1) $\mathrm{TTS}_{2}$ is a consistent measure of the effects of a single day's exposure; (2) all exposures producing a given $\mathrm{TTS}_{2}$ will be equally hazardous; and (3) noise-induced PTS (NIPTS) produced after many years of habitual exposure will be the same as the $\mathrm{TTS}_{2}$ produced in normal ears by an 8-hour exposure to the same noise. ${ }^{4}$ After several modifications involving repeated simplifications (see Suter ${ }^{2}$ ), these criteria were eventually adopted in 1969 by the Department of Labor under the authority of the Walsh-Healey Public Contracts Act, using a simple $5-\mathrm{dB}$ relationship between level and duration or ER. ${ }^{15}$ This noise standard became an OSHA standard with the passage of the Occupational Safety and Health Act in 1970.

Meanwhile, the international community adopted the 3-dB ER in ISO standard 1999, ${ }^{12}$ and the U.S. EPA. ${ }^{16}$ The U.S. Air Force adopted the 3-dB ER as early as 1956, changed to a 4 - $\mathrm{dB}$ ER in 1973 , then back to $3 \mathrm{~dB}$ by 1993.* Later versions of ISO 1999 have retained the 3-dB ER..$^{13,17-21}$ ANSI S3.44 also uses the 3-dB ER, although it mentions the possible use of the 5-dB ER under certain conditions. ${ }^{22}$

Both the 3-dB and the 5-dB ERs have been the subject of criticism. Although the CHABA criteria reflected a thorough attempt to predict the hazard from many different exposure patterns, the subsequent drive for simplicity caused the abandonment of some of its more nuanced features. The result was the $5-\mathrm{dB}$ rule, an ER that allowed single exposures of high-level, uninterrupted noise for as long as 15 minutes, which has been

\footnotetext{
Other branches of the military also alternated between various exchange rates. In 1972 the U.S. Army's Technical Bulletin TB Med 251 published criteria using a 5-dB ER starting at $85 d B A .{ }^{144}$ The $E R$ was later changed to $4 d B$ for risk assessment. ${ }^{145}$ For several years hearing conservation requirements were contingent upon exposure to $85 \mathrm{dBA}$ regardless of time, but in 1994 the Army switched to timeweighted average based on a 3-dB ER. ${ }^{146}$ The U.S. Navy employed a 4-dB ER beginning in 1994, ${ }^{147}$ then changed to $3 d B$ in 2008. ${ }^{148}$ Currently the Department of Defense requires the 3-dB ER in all branches of the military service. $^{70}$
} 


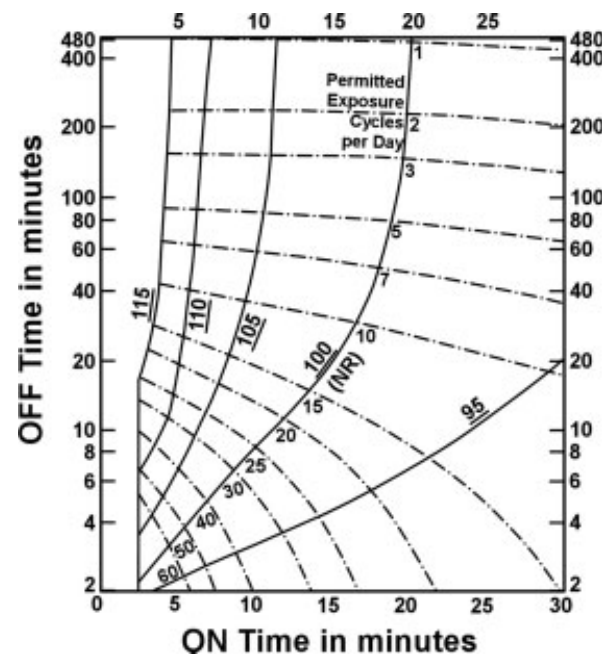

Figure 4 Curves for rating allowable exposure cycles per day for noncontinuous noise as a function of noise level, on-time and off-time (from Glorig et $\mathrm{al}^{14}$ ). Permissible number of exposure cycles per day consisting of various on-times (horizontal axis) and off-times (vertical axis) and noise rating numbers (NR) from 95 to $115 \mathrm{~dB}$.

considered excessive. The CHABA criteria also have been criticized because of the considerable magnitude of hearing loss they allowed (e.g., for the $3000-\mathrm{Hz}$ frequency a median NIPTS of $20 \mathrm{~dB}, 40 \mathrm{~dB}$ for the 20th percentile, and $60 \mathrm{~dB}$ for the 10th percentile). In fact, all of the CHABA postulates have been called into question since that time, which will be discussed in greater detail herein.

The 5-dB ER was based on the assumptions that there would be evenly spaced intermittencies of uniform duration and sufficient levels of quiet or effective quiet between exposures during the 8-hour workday to prevent excessive amounts of hearing loss. ${ }^{\dagger}$ Unfortunately, such conditions are not usually characteristic of occupational noise exposures. ${ }^{23}$

On the other hand, the 3-dB ER has been criticized for its failure to take the ameliorative effects of interruptions into account. Research on both animal and human populations has shown that under certain circumstances, inter-

\footnotetext{
${ }^{+}$The level of effective quiet that would permit recovery from TTS appears to be variable according to stimulus as well as audiometric frequency, ranging from about $65 \mathrm{~dB}$ for higher frequencies to $70 \mathrm{~dB}$ for lower frequencies.
}

ruptions in noise exposure schedules can be beneficial in reducing the amount of hearing loss predicted by the $3-\mathrm{dB} E R .^{24-27}$

\section{Laboratory Studies of Animals}

Early research on laboratory animals examined TTS, ATS, and PTS as dependent variables, but soon began to include loss of OHCs and IHCs, mainly in the chinchilla model. As a whole, these studies provided evidence that the 3-dB ER applies to single exposures of various levels and durations within an 8-hour day. ${ }^{28-30}$ The $3-\mathrm{dB}$ rule appeared to have its limits, however, and intermittent exposures, such as $6 \mathrm{~h} / \mathrm{d}$ for 36 days, caused much less damage than single uninterrupted exposures, such as 9 days of continuous noise at an equivalent energy level. ${ }^{31}$ Thus the total energy hypothesis was shown not to apply, albeit continuous exposures of this length are rare in most occupations, where the 8- to 10-hour workday followed by 14 to 16 hours away from noise is more typical. Some investigations showed that different kinds and levels of damage occurred at different locations along the organ of Corti's basilar membrane, ${ }^{31,32}$ and they raised the possibility that protection of the basal portion of the cochlea might require the $3-\mathrm{dB}$ rule even when intermittent exposures are spread out over long periods. Several of these investigations showed that intermittencies under laboratory conditions produced significantly less TTS, PTS, and loss of OHCs and IHCs than continuous noise of equivalent energy, although most of these exposure patterns were not characteristic of noisy workplaces. Some of these findings would be replicated in later research (see later discussion).

\section{Field Studies of Workers}

Nearly all of the early field studies of noise exposure and hearing loss have some weaknesses, such as small sample sizes and inadequate noise measurement data. Another common weakness is the sporadic wearing of hearing protection devices (HPDs), whose attenuation cannot be accounted for because its effect is unknown. Despite their shortcomings, field studies of working populations have been 
considered useful when taken as a group, where trends have become apparent.

One of the best-known early investigations is that of Burns and Robinson, ${ }^{33}$ whose exposures were reasonably steady and not markedly impulsive in character, although some subjects were exposed to a variety of noise levels. The pool of 759 subjects had been thoroughly screened to exclude nonoccupational exposures and otologic disorders. The $\mathrm{L}_{2}$ statistic (the level exceeded $2 \%$ of the time) appeared to be the best descriptor of hearing loss, but the simple energy equivalent ( $\mathrm{L}_{\text {eq }}$ or $3-\mathrm{dB} \mathrm{ER}$ ) was a very close second. The authors proceeded to use the $\mathrm{L}_{\mathrm{eq}}$ for predictions of hearing loss in various percentages of populations with daily exposures ranging from several months to many years. ${ }^{34}$

A study by Evans and Ming examined the effects of noise on 300 workers in Hong Kong in a variety of occupations, including continuous noise environments (textile workers) and noncontinuous environments, such as metal working, bottling, and aircraft maintenance. ${ }^{35}$ Age-corrected hearing levels for continuous exposures followed the $3-\mathrm{dB}$ rule, whereas the noncontinuous groups showed more hearing loss than would have been predicted by the $3-\mathrm{dB}$ rule. The investigators believed that the explanation lay in their use of an unscreened subject pool, and after adjusting the data by $5 \mathrm{~dB}$, most of the noncontinuous groups fell within the ISO predictions.

During the 1970s, however, several field investigations reported less hearing loss than would be predicted by the $3-\mathrm{dB}$ ER in the ISO 1999 standard. ${ }^{25,26,36}$ Certain European investigations of miners reported by Ward also appeared to support the benefits of intermittency. ${ }^{37}$ Two studies by NIOSH failed to confirm those findings, but results were inconclusive about which ER actually best predicted the hearing levels from intermittent exposures. ${ }^{38,39}$

\section{Passchier-Vermeer's Analysis}

Probably the most comprehensive investigation of the effects of intermittent and varying noise was that of Passchier-Vermeer, ${ }^{3}$ who selected 11 out of 100 pertinent studies based on such factors as adequacy of noise exposure data, total exposure time of at least 10 years, a difference of at least $25 \mathrm{~dB}$ between the highest and lowest exposure levels, and screening procedures used by each investigator. In her analysis, PasschierVermeer divided subjects into 20 groups according to whether their exposures were varying or intermittent, the durations of the noise bursts, and the 8-hour $\mathrm{L}_{\mathrm{eq}}$. With the results of her analysis of the hearing loss due to intermittent and varying noise, she compared data points from intermittent and varying noise to her own curves for continuous noise exposure. She also compared these data points to curves developed by Burns and Robinson based on the $\mathrm{L}_{\mathrm{eq}}{ }^{33}$ The results, shown in Fig. 5, compare the data points for the $3,000-\mathrm{Hz}$ frequency from PasschierVermeer's varying (circles) and intermittent (squares) noise exposures to her data from a previous analysis for 15 years of continuous noise exposure. ${ }^{3,40}$ These results show generally good agreement between her data for continuous noise and those of the intermittent and varying noise analysis.

Fig. 6 shows the relationship between Passchier-Vermeer's varying and intermittent data points to the equal energy curve developed by Burns and Robinson, also for 15 years of noise exposure and the $3,000-\mathrm{Hz}$ frequency. ${ }^{33}$

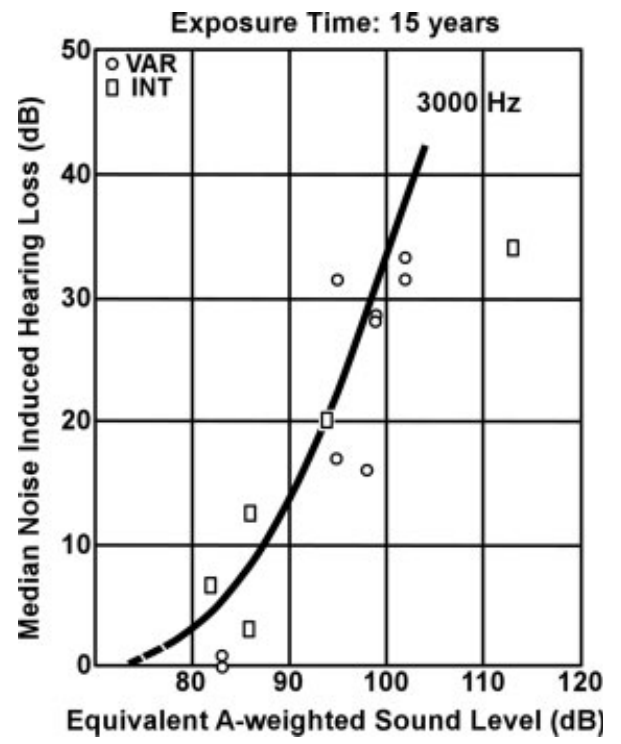

Figure 5 Median noise-induced hearing loss at $3,000 \mathrm{~Hz}$ for varying (VAR; circles) and intermittent (INT; squares) as a function of equivalent A-weighted sound level. Curve represents Passchier-Vermeer's estimates for hearing loss due to 15 years of continuous noise exposure (from PasschierVermeer ${ }^{3}$ ). 


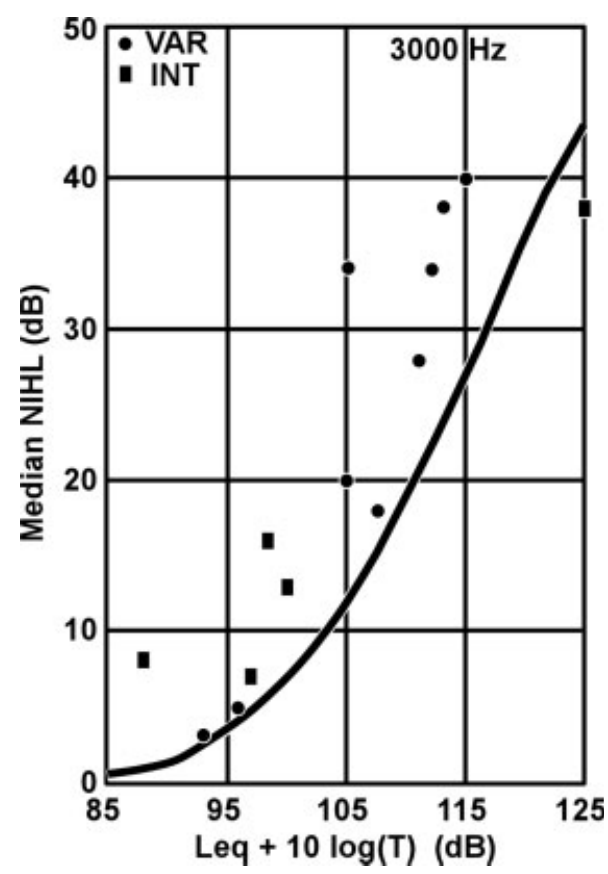

Figure 6 Median noise-induced hearing loss (NIHL) at 3,000 Hz for varying (VAR; circles) and intermittent (INT; squares) noise as a function of noise "immission" level $\left(L_{e q}+10 \log T\right.$, where $T$ is the exposure time in years). Curve represents estimates of Burns and Robinson ${ }^{33}$ for hearing loss due to 15 years' exposure to continuous noise (from PasschierVermeer ${ }^{3}$.

In this case, the data points for intermittent and varying noise fall above the equal energy curve, indicating more hearing loss than the Burns and Robinson curve would have predicted. This result is not surprising in that PasschierVermeer's hearing threshold data for continuous noise also showed slightly more hearing loss than those of Burns and Robinson at and above $2,000 \mathrm{~Hz}$, which may have been related to the differing amounts of screening in the data sets. She concludes from these comparisons that the equal energy rule describes hearing loss from intermittent and varying noise quite well.

\section{Shaw's Analysis}

Shaw re-examined Passchier-Vermeer's analysis and compared the results to those that would be predicted by the new (at that time) ISO 1999 standard, assuming that the growth of median NIPTS would follow the mathematical func- tions incorporated into the standard. ${ }^{41}$ The results of Shaw's analysis showed general agreement for the varying and intermittent groups with the ISO predictions for all frequencies except $6,000 \mathrm{~Hz}$, where the data points fell above the ISO curve, indicating more hearing loss for intermittent and varying noise than would have been predicted. If the analysis were to support the $5-\mathrm{dB} \mathrm{ER}$, there would have been a systematic displacement of the data points below the curve, which was not the case for any frequency.

\section{Conclusions from 1992 Report}

The analyses of the field studies by PasschierVermeer and Shaw support the contention that hearing loss from interrupted and varying noise exposures may be predicted by the equal energy or 3- $\mathrm{dB}$ rule (ER). ${ }^{3,41}$ However, certain studies of workers exposed to intermittent noise have shown less hearing loss than would be predicted. This appears to be particularly true of outdoor occupations where there can be large differences between high and low noise levels and periods of relative quiet between noise bursts. By contrast, most indoor noise environments are characterized by the buildup of reflected sound, which provides relatively little benefit from intermittency. Examples of outdoor occupations characterized by intermittencies would be forestry and open-pit mining.

If indeed certain noise exposures proved to be less damaging to hearing than continuous noise environments, an adjustment (increase) could be made to the overall REL as opposed to the selection of a different ER. One could consider the REL as the intercept point on the dose-response curve, and the ER represents the curve's slope. Adjusting the REL for certain exposure conditions could be accomplished without compromising the ER. The amount of such an adjustment would need to be determined by the temporal pattern of the noise and the levels of quiet between noise bursts. At present, there is little quantitative information available for these parameters in real-world occupational environments, and any such adjustments are unlikely to be appropriate in most indoor work environments. Even if certain occupational noise conditions would prove to 
qualify for such an adjustment to the REL, that would not justify the use of the 5-dB ER. When reviewing these studies, one should remember that temporary and even permanent shifts of auditory acuity cannot be considered definitive of auditory damage - they are only indicators.

\section{LABORATORY INVESTIGATIONS SINCE THE 1992 REPORT}

Learning Outcomes: As a result of this activity, the participant will be able to describe two laboratory investigations that have been completed since the 1992 report that changed our understanding of the impact of noise exposure.

Between 1992 and the present, numerous studies have been cited to support the ameliorative effect of interrupted exposures and therefore challenging the use of the 3-dB ER, some of them more convincingly than others.

\section{Benefits of Intermittency}

In recent years, some of the animal studies mentioned briefly in the 1992 report have frequently been cited as supporting the benefits of intermittency, in particular a study by Clark et al. $^{42}$ In this experiment, chinchillas were exposed to a $500-\mathrm{Hz}$ octave band of noise at $95 \mathrm{~dB}$ continuously for 6 hours per day for 36 days. Others were exposed for 15 minutes per hour for 144 days, the two exposures being of equivalent energy. This study was weakened by significant shortcomings. Postexposure and cell loss data for the intermittent group were missing, there was minimal PTS in the continuous noise group against which to compare, and the study used a very small number of subjects. Thus the authors' conclusion that intermittent exposures produce less permanent hearing loss and cochlear damage than continuous exposures was not adequately supported by the data. The investigation did, however, reveal an improvement in HTLs in both groups as the exposure continued. This improvement, which would later be referred to as toughening, was more noticeable in the animals exposed to intermittent noise.

A follow-on experiment by Sinex et al to further explore the toughening phenomenon used the same stimuli and intermittent exposure pattern, this time for 4 or 40 days. ${ }^{43}$ The results showed similar improvements in thresholds approaching pre-exposure thresholds to within 5 to $15 \mathrm{~dB}$ even though the exposure continued. Histologic examination, however, revealed little correlation between the extent of hair cell loss and threshold shift (TS), indicating that any apparent toughening as a result of intermittent noise did not signify a decrease in damage to the auditory system. This phenomenon is discussed in greater depth later in this report.

Several other animal experiments also have produced benefits from intermittencies, albeit in less than realistic conditions. Fredelius and Wersäll exposed guinea pigs to $3.85-\mathrm{kHz}$ pure tones at levels of 108,114 , and $120 \mathrm{~dB} .{ }^{44}$ The investigators compared a one-time exposure for 6 hours to two 3-hour exposures with a 1-hour break in between. The results showed a significant reduction in cell damage caused by the intervening rest period in two of the three exposure level groups.

In another experiment using guinea pigs, Pourbakht and Yamasoba tested the effects of an octave band of noise centered at $4 \mathrm{kHz}$ in continuous and interrupted modes at two levels, $115 \mathrm{~dB}$ and $125 \mathrm{~dB}^{45}$ The intermittent exposures consisted of 2 pulses per second with a $45 \%$ duty cycle. Not surprisingly, the intermittent exposure produced significantly less PTS and cell loss than the continuous exposure. The investigators compared the outcome of groups exposed to the same sound levels but not of equivalent energy because the intermittent exposure used a $45 \%$ duty cycle. The results did show a benefit of intermittency in the $125-\mathrm{dB}$ intermittent group compared with the $115-\mathrm{dB}$ continuous group in row 1 of the OHCs but not in rows 2 and 3 .

Patuzzi, ${ }^{46}$ in another investigation cited to support the benefits of intermittency, measured TTS growth and recovery for a $5-\mathrm{kHz}$ pure tone stimulus with varying on-times, using only one subject (himself). The author found considerably less TTS than predicted with the intermittent exposure, and he also observed differences in the recovery course. Recovery curves for intermittent exposures appeared flatter, but followed approximately the same time course.

Lataye and Campo also used the guinea pig model to test various moderate noise levels for three intermittent conditions against a 
continuous exposure of equivalent energy $-8 \mathrm{~h} / \mathrm{d}$ for 14 days. ${ }^{47}$ The stimulus was a one-third octave band of noise centered at $8 \mathrm{kHz}$ in short-continuous, interrupted (defined as 1 second or longer) or impulsive ( 0.2 to 1 second duration) conditions, all with an 8 -hour $\mathrm{L}_{\text {eq }}$ of $92 \mathrm{~dB}$. The results showed significantly less PTS for the intermittent conditions than for the continuous exposures, except that a 4-hour exposure at $95 \mathrm{~dB}$ produced the same PTS as 8 hours at $92 \mathrm{~dB}$, as would be predicted by equal energy and as found by other investigators. ${ }^{27}$ The impulse condition produced slightly (but not significantly) more PTS than predicted. With PTS as the criterion, the 3-dB ER seemed to be the best predictor for longer noise episodes (as $95 \mathrm{~dB}$ for 4 hours) and for the higher noise levels ( $\sim 108$ and above). For the other intermittent conditions, the 5-dB ER seemed a better fit to the data. With regard to cell damage, however, surface preparations showed greater than expected cell loss for most conditions even when there was less PTS. Scanning electron microscopy used to assess the condition of the hair cell stereocilia showed damage consistent with equal energy for some conditions and more than predicted for others. Based on PTS data, the authors concluded that the $5-\mathrm{dB}$ ER provides a better fit than the 3-dB ER for moderateintensity interrupted noise. However, they found very poor agreement between PTS and cell damage, including structural changes and stereocilia abnormalities.

Although the above experiments may be of interest, they are not always useful in predicting the extent of real savings by intermittency for several reasons: (1) the number of subjects is often quite low and may have been insufficient to draw reasonable conclusions; (2) exposures to continuous versus intermittent noise were not always of equal energy; (3) stimuli consisting of pure tones, although they may be more satisfactory for comparability, are not realistic (and the same might be said of narrow bands of noise); (4) both TTS and PTS have proved to be poorly related to cochlear damage; and (5) experimental conditions of stimuli consisting of evenly spaced noise bursts interspersed with periods of effective quiet are not characteristic of most occupational environments.

\section{Systematic Reviews}

Two publications that constitute summaries of many experiments involving many animals may shed further light on the subject of the ameliorative properties of intermittency: $\mathrm{Ward}^{27}$ and Harding and Bohne. ${ }^{24}$

In 1991, Ward reported on a series of experiments conducted over many years involving interrupted, intermittent, and time-varying noise exposures using the chinchilla model. ${ }^{27}$ As in most other animal experiments, Ward's results assume sound levels of effective quiet during the intermittencies. The results supported equal energy for some conditions but more lenient ERs in several others. Daily 8-hour exposures at $92 \mathrm{~dB}$ for 9 weeks produced approximately the same PTS and OHC loss as 0.8 hours at $102 \mathrm{~dB}$, supporting the equal energy approach for these conditions. However, both exposures produced less loss than a continuous exposure of equivalent energy for 15 days, thus countering the "total energy" theory. In other words, they validated what was already known: that the equal energy theory was based on daily exposures, not on uninterrupted exposures for indefinite time periods, such as weeks or months.

Ward's analysis showed that although breaks as long as 16 to 24 hours had little ameliorative effect, shorter pauses and shorter durations did show benefits. ${ }^{27}$ For example, breaking daily noise exposures into small segments, such as 40 noise bursts of 1.2 minutes presented every 12 minutes, produced a reduction in both PTS and $\mathrm{OHC}$ loss over longer noise bursts of equivalent energy. Ward concluded that controlling the duration of bursts and pauses can produce a reduction in damage and that both were "important in some complicated way." $27($.107) He hypothesized three possible explanations for the benefits he observed from intermittencies: (1) recovery from auditory fatigue during periods of effective quiet; (2) restoration of middle ear muscle function during pauses; and (3) a positive effect from the efferent protective system.

Harding and Bohne presented a retrospective analysis of several experiments conducted at their laboratory consisting of a total of 416 chinchillas exposed to octave bands of noise centered either at $500 \mathrm{~Hz}$ or $4 \mathrm{kHz}{ }^{24}$ These experiments built on a series of previous studies. ${ }^{31,48,49}$ Loss of OHCs and IHCs was assessed 
as a consequence of exposure to a wide range of sound levels and temporal patterns. Exposure durations for the $500-\mathrm{Hz}$ octave band ranged from 3.5 hours to 432 days and for the $4-\mathrm{KHz}$ band from 0.5 hours to 36 days. One important parameter of this experiment was to test the primary versus secondary effects of these exposures by examining cell loss immediately after exposure cessation compared with cell loss after postexposure recovery times of up to 365 days.

Several findings about intermittent exposures emerged from the Harding and Bohne studies ${ }^{24}$ : above a critical level (in this case 86 to $90 \mathrm{~dB}$ for $4 \mathrm{kHz}$ and $\sim 95 \mathrm{~dB}$ for $500 \mathrm{~Hz}$ ), there was more damage than would have been predicted by $\mathrm{L}_{\mathrm{eq}}$, but no relation between total energy and cell loss. Below the critical level, rest periods usually had a significant benefit, which was dependent upon stimulus frequency, location on the basilar membrane, the time at which the effects were assessed (during exposure or after a recovery period), and whether the dependent variable was IHCs or OHCs. For example, rest periods were not beneficial for IHCs in the cochlear base, although the $\mathrm{OHCs}$ did benefit in this area. In addition, the results showed that the majority of $\mathrm{OHC}$ loss from the 4-kHz band occurred after the exposure had ended, and $\mathrm{OHC}$ loss from the $500-\mathrm{Hz}$ band occurred during exposure. The majority of IHC loss occurred postexposure. This latter finding calls into question the results of earlier investigations where histologic assessment occurred only at the cessation of exposure. In those cases where postexposure damage was assessed, it raises the question as to whether these waiting periods were long enough.

The analysis of this series of studies by Harding and Bohne shows, ${ }^{24}$ at least under certain laboratory conditions, that rest periods between exposures can provide significant benefits in terms of cochlear cell loss. However, the relationships between the various parameters of level, frequency, type of cell, location of damage along the basilar membrane, and time of assessment are highly complex.

\section{Issues Relating to the Effects of Intermittency}

The experiments on the benefits of intermittencies described here raise certain issues, some of which have been addressed by other researchers. These include the toughening phenomenon and delayed recovery with intermittent and particularly with impulsive exposures. Also of perennial interest is the translation from animal models to humans.

\section{TOUGHENING}

Experiments like those conducted by Clark et al and Sinex et al showed previously unexplained improvements in TSs during noise exposures, ${ }^{42,43}$ especially during exposure to intermittent noise. This phenomenon, which appears as a reduction in TS, has been observed by other investigators and has been referred to as toughening. ${ }^{50}$ Boettcher et al found significant reductions in TS during intermittent exposures, especially at the lower frequencies, but that $\mathrm{OHC}$ loss and stereocilia damage continued to spread toward the cochlear base as exposure continued. ${ }^{51}$ They also found that the TS did not always return to normal at the end of the exposure, particularly for the highest frequencies tested.

Hamernik and Ahroon investigated the toughening phenomenon in a larger group of chinchillas $(n=266)$ using 32 exposure conditions, which included an uninterrupted 5-day exposure to continuous noise for comparison to various interrupted schedules over a 20-day period. ${ }^{52}$ The stimuli were narrow bands of noise (400 $\mathrm{Hz}$ wide) from 500 to $8 \mathrm{kHz}$ at a rate of one impact per second, 24 hours per day for 5 days, or one impact per second, 6 hours per day for 20 days, with peak sound pressure levels (SPLs) of 109, 115,121 , and $127 \mathrm{~dB}$, all of equivalent energy. The investigators found a significant toughening effect and some improvements in PTS between the continuous group and one of the four interrupted groups, but no statistically significant differences in $\mathrm{OHC}$ or IHC loss between groups. From this extensive set of animal data, they concluded that the toughening phenomenon produced by interrupted noise exposures may result in slightly less PTS, but that it is not protective of the cochlea. These results were later confirmed by other investigations. ${ }^{53,54}$ Although the authors state that the "concept of equal-energy damage is overly conservative for interrupted exposures that allow for recovery processes to intervene between exposure cycles," ${ }^{52}$ it is clear that they refer to PTS rather than cochlear cell loss. 
Qiu et al furthered these investigations by examining the effects of differing interrupted, intermittent, and time-varying exposures modeled after an idealized 3-week work schedule. ${ }^{55}$ With a total of 74 chinchillas, two groups exposed to uniform levels of noise at 100- or 106-dB SPL for $24 \mathrm{~h} / \mathrm{d}$ for 5 days were compared with animals with interrupted, intermittent, and time-varying exposures of equivalent energy ranging from 90 to $108 \mathrm{~dB}$ or 80 to $115 \mathrm{~dB}$, respectively. In contrast to other similar experiments, the authors studied more moderate noise exposure levels and also added time-varying noise conditions to other intermittency patterns. All of the interrupted exposures produced a toughening effect, which was greatest in the lower frequencies. However, neither PTS nor cell loss was reduced in comparison to the uninterrupted reference exposures.

\section{DELAYED RECOVERY FROM TEMPORARY THRESHOLD SHIFT}

In both animal and human subjects, recovery from TTS due to continuous noise exposure has usually followed a linear function in log time. Nearly 50 years ago, Ward noticed that normalhearing students exposed to high-frequency, high-level noise, either as long or short bursts, exhibited delays in their recovery from TTS. ${ }^{56} \mathrm{~A}$ nonlinear recovery pattern generated by impulse noise has been documented by Luz and Hodge and from both impulse and impact noise by several other investigators since that time. ${ }^{8,57-61}$ In addition to a prolonged recovery period, the pattern may show some immediate recovery, then growth in TS reaching a second peak between 1 and 10 or more hours postexposure. The pattern and magnitude of these effects appears to be related to stimulus frequency, level, and temporal parameters. Delayed recovery from TTS could have a negative effect on the ear's ability to recuperate between exposures and would help to explain the increase in the damaging potential of impulse/impact noise documented in many investigations.

\section{TRANSLATING FROM ANIMAL MODELS TO HUMANS}

Most of the animal experiments over recent decades have used the chinchilla model, although a few have used the guinea pig. Bohne and Harding have described the chinchilla as an excellent model for studying the effects of noise on humans. ${ }^{49}$ Its audibility curve is similar to that of humans in the frequencies at which both species are maximally sensitive, and the patterns and progression of noise-induced damage appear to be very similar to humans. The chinchilla has a long life span, which is convenient for assessing the effects of long exposures, and its middle and inner ears are surgically accessible so that it may be rendered monaural. The chinchilla appears to be somewhat more sensitive to noise than humans. Trahiotis estimated a $20-\mathrm{dB}$ increase in sensitivity of the chinchilla over the human auditory system. ${ }^{62}$ Harding and Bohne postulated a $10-\mathrm{dB}$ increase, citing the extensive research of Eldredge et al. ${ }^{24,63}$ This estimate is particularly important with respect to the issue of the critical level.

Ward points out that the chinchilla's recovery from noise is somewhat slower than that of humans, as he found that little recovery occurred from even moderate values of TTS during the first 4 to 8 hours following exposure. ${ }^{27}$ Ward believes that this delay might explain the failure of rest periods as long as 16 hours to reduce the damage in his animals with 8-hour continuous exposures, although he questions why short interruptions had such a large ameliorative effect. If delayed recovery were unique to the chinchilla, this could affect the translation from the chinchilla model to humans. Humans, however, also have demonstrated various states of delayed recovery. ${ }^{56,64,65}$

\section{IMPULSE NOISE}

Learning Outcomes: As a result of this activity, the participant will be able to describe the issues related to characterizing risk of exposure to impulse noise and the complexities associated with developing consensus occupational guidelines.

Before discussing the effects of complex noise in more detail, it would be helpful to examine the effects of noise exposures that are predominantly impulsive. Occupationally, these exposures are mainly found in the military, but in some civilian occupations as well, especially among police officers, other public safety personnel, and certain 
occupations in the construction industry. They may be differentiated from impact noise, which occurs primarily in manufacturing occupations and construction, although there is necessarily some overlap.

Professionals in acoustics have struggled over definitions of impulse and impact noise for decades. Traditionally the difference between impulse and impact noise is that the former is a high-level transient resulting from a sudden release of energy into the atmosphere, and the latter is a high-level transient resulting from the impact between two objects.

The U.S. Department of Labor has defined impulse noise by default. Section (b)(2) of the noise regulation states that if variations in noise level involve maxima at intervals of 1 second or less, it is considered continuous noise. ${ }^{66}$ The footnote to Table G-16 of the regulation states that exposure to impulsive or impact noise should not exceed 140-dB peak SPL; this statement may be considered advisory rather than a requirement.

\section{Impulse Noise Criteria and Standards}

Various attempts to develop damage-risk criteria have paid attention to factors in addition to peak pressure level, such as rise time, pressure wave duration, pressure envelope duration, frequency spectrum, and number of impulses. Early attempts, such as the CHABA criteria, recommended limitations for both A-duration and B-duration impulses and employed a trading relation between intensity and the number of impulses. ${ }^{67}$ Such a scheme was proposed by OSHA in 1974, but was never promulgated. ${ }^{68}$

In 1997, the Department of Defense issued MIL-STD 1474D, which included criteria for numbers of impulses as well as peak SPL and impulse B-duration. ${ }^{69}$ The standard provided specific noise limits for designers and manufacturers supplying equipment and weaponry to the U.S. military. This standard has been superseded by MIL-STD $1474 \mathrm{E},{ }^{70}$ which no longer includes criteria for numbers of impulses.

In recent years, several sets of criteria have been developed, mainly for use in predicting hearing damage from weapons noise. Principal among these, at least in the U.S., have been the Auditory Hazard Assessment Algorithm for the Human (AHAAH) developed by Price and his colleagues and the $\mathrm{LA}_{\mathrm{eq}} 8$-hour model developed by a French team and modified by U. S. scientists as described later. ${ }^{71-75}$

The AHAAH system is an electroacoustic model based on the response to impulsive sound by the cochlea's basilar membrane. It was developed using the cat cochlea, modeled by a 23-element network transmission time approximating 1/3-octave band intervals. Damage to hearing by an impulse is calculated for each location along the basilar membrane by estimating the sum of the square of positive displacements in microns. The model includes the use of a "warned" or "unwarned" condition, depending upon whether or not the middle ear muscles have been activated through classical conditioning or a priming sound prior to the impulse waveform.

The $\mathrm{LA}_{\mathrm{eq}} 8$-hour is based on the integrated A-weighted sound level for an equivalent 8-hour exposure, adjusted for duration and the number of impulses. A modification of this metric was developed by Hamernik et al, ${ }^{76}$ which replaced the 8 -hour term with a 1 -second term in the calculation of equivalent energy. This metric became known as SELA (A-weighted Sound Exposure Level).

Much of the work on evaluating the effectiveness of various impulse noise models has been done by Murphy and colleagues at NIOSH. ${ }^{77-79}$ The NIOSH team has collaborated with several researchers in the military who have conducted a series of TTS experiments using human volunteers, referred to as the "Blast Overpressure Project" or the "BOP." ${ }^{80,81}$ As part of the BOP study, Hamernik and his team extended the research to the chinchilla model, further exploring the results in terms of PTS and anatomical pathology over a wide range of impulse noise exposures. ${ }^{76}$

Variants of each of these methods have now been published in the most recent Department of Defense Design Criteria Standard for Noise Limits, MIL-STD-1474E. ${ }^{70}$ Users of these criteria are given a choice between the Auditory Risk Unit, which is calculated using the AHAAH model, or the $\mathrm{L}_{\mathrm{IA} \text { eq100ms }}$ model to predict auditory hazard. Use of the AHAAH requires the appropriate software and expertise. According to Appendix B of ML-STD$1474 \mathrm{E},{ }^{70}$ the AHAAH model has been peer- 
reviewed and systematically evaluated against various data sets; however, the American Institute of Biological Sciences recommends further research and validation of certain of its critical assumptions, especially with regard to the influence of the middle ear reflex.

The other alternative in MIL-STD-1474E is the $\mathrm{L}_{\mathrm{IAeq100ms}}$, a variation of the $\mathrm{L}_{\mathrm{ICeq} 8}$ metric tailored for impulse noise, which represents the equal energy equivalent of the sound exposures averaged over 100-millisecond intervals. No computer program is required for this method. The standard states that the $\mathrm{L}_{\mathrm{eq} 8}$ has an empirical foundation based on human response to impulsive noise but that it can overestimate the hearing damage risk for long duration impulses. Therefore, the $\mathrm{L}_{\mathrm{IAeq} 100 \mathrm{~ms}}$ method includes a correction for long A-duration impulses (i.e., A-durations more than 0.2 milliseconds). ${ }^{70}$ Simplicity as well as its relevance to complex noise environments would argue for the method based on $\mathrm{L}_{\text {eq8 }}$.

\section{Critical Level}

High levels of impulse noise in certain environments led to the study of "critical levels" of noise exposure, beyond which damage to hearing rises sharply with increases in exposure parameters, particularly with increases in sound level. In one of these early investigations, Luz and Hodge developed a model to explain delayed recovery from TTS in terms of mechanical and metabolic damage to the cochlea from impulse noise. ${ }^{57}$ Metabolic damage is evident with recovery beginning immediately postexposure, and edema from mechanical damage often leads to a bounce or growth in TS manifest in a second peak, after which hearing begins to return toward normal levels. Henderson et al and Hamernik et al have found this multiphase recovery in chinchillas exposed to high levels of impulse noise at 155 to $160 \mathrm{~dB}$ and concluded that mechanical damage occurred at these levels. ${ }^{58,82}$ Spoendlin observed the effects of direct mechanical destruction in cats for a 200 -millisecond stimulus at $120 \mathrm{~dB} .^{83}$

With the chinchilla model, Roberto et al used a 200-millisecond B-duration impulse with four impacts per second. ${ }^{84}$ They found that exposures between 107 and $119 \mathrm{~dB}$ produced effects consistent with equal energy, but at a level of $125 \mathrm{~dB}$ substantially more damage occurred, indicative of a critical level. In a subsequent investigation using the same noise stimulus, Henderson et al estimated the critical level in chinchillas to be between 119 and $125 \mathrm{~dB}$. Further investigations by members of the same team confirmed that range for the critical level. ${ }^{59}$ The authors concluded that the critical level varies not only with peak level, but with waveform, spectrum, duration, and repetition rate. ${ }^{59,60,85,86}$ Using the guinea pig model, Lataye and Campo estimated a critical level of $111 \mathrm{~dB} .{ }^{47}$

Rather than producing some kind of savings from intermittency, the conditions in the preceding experiments involving impulse/impact noise seem to follow an equal energy pattern at lower levels until they reach a critical exposure, at which point the damage to hearing is greater than would be predicted. The concept of the critical level is important to the discussion of the ER in that any adjustments to an ER that best fit hearing loss predictions need to take into account the effects of impulses and impacts, and in this case, the critical levels or exposures. Although the specific parameters may not be completely spelled out at this time, these adjustments could eventually be accomplished through the development of appropriate measurement methods and instrumentation.

\section{COMPLEX NOISE}

Learning Outcomes: As a result of this activity, the participant will be able to describe how measurements of kurtosis can improve methods for predicting the hearing damage risk associated with nonGaussian noise.

Most of the animal experiments discussed previously have used various noise patterns involving time-varying, interrupted, or intermittent stimuli, the exception being those cited on the issue of the critical level, which used impulse or impact noise. But most of the others consisted of various durations of octave- (or wider) bands of steady-state noise, interrupted by periods of silence. These investigations, although yielding useful information, are conducted in conditions that are not typical of most workplaces. 
In fact, a great many workplace noise exposures consist of complex noise due to the participation of several sources. Noise can be air- or structure-borne, and acoustic signals can be changed or augmented by reflections from the floor, walls, ceiling, and machinery surfaces, as in Fig. 3. There may be considerable differences in the hazard from indoor and outdoor occupations because of these reasons. The frequency spectrum as well as the level can be modified, depending on whether the conditions are a free field, quasi-free field, or reverberant field. Occupational noise exposures are typically broad in spectrum, which is true of impulse and impact noise as well as noise that is steady-state. The C-weighted minus A-weighted values of most occupational exposures are only 2 to $3 \mathrm{~dB},{ }^{87,88}$ indicating a lack of significant lowfrequency dominance in most cases.

Certain occupations consist primarily of the steady-state, continuous noise typically found in power plants, textile weaving and spinning plants, and paper mills, although even these noise environments are sometimes interrupted by high-level transients. Others are characterized mainly by impulse noise, such as police and military occupations, or impact noise, which is frequently found in the construction trades. However, it is more common that impulses and impacts are superimposed on a background of continuous or varying noise. Impulse noise may occur at levels from $\sim 100$ to $>185 \mathrm{~dB}$ and typical levels of impacts could be $\sim 95$ to 135 dBA. ${ }^{60,89}$

Occupations where exposures are primarily impulsive also may include relatively high levels of background noise. For example, law enforcement officers and military personnel who must train regularly in firearm use often do so at indoor firing ranges. Although the primary exposures to those individuals are impulses generated from their firearms (typically reaching 150 to $165 \mathrm{~dB}$ SPL), the ventilation systems at indoor firing ranges must generate large air flows between 50 and 75 feet per minute. Noise levels from ventilation systems range from 77 to $84 \mathrm{dBA}$ and those systems must be constantly operated during the firearms exercises. ${ }^{90}$ Another example would be a mounted weapon system in the military, where the noise levels of an armored vehicle or helicopter could be $100 \mathrm{~dB}$ SPL and impulses rise periodically above that level. Many other examples can be found in construction, mining, and manufacturing, where impulse or impact noises are present over machines or tools generating continuous noise in the background (e.g., saws and nail guns in construction or continuous miners and roof bolters in mining). In these kinds of environments, conventional measures such as peak SPL and averages are probably not adequate to assess the hazard to hearing.

The data in Table 1 reveal the large differences between peak and average sound levels in several common occupations.

\section{Measurement of Complex Noise}

One of the most difficult problems with complex noise in general and impulse noise in particular has been how to measure it. Not only does any measurement scheme need to be based on the type and level of noise consistent with appropriate hearing damage criteria, but the instrumentation needs to be adequate to do the job.

In 2003, NIOSH sponsored a meeting devoted to the subject of impulse noise. ${ }^{89}$ Participants discussed the need to develop a practical means to evaluate impulse noise, including exposures to a mixture of continuous, intermittent, and impulsive sounds. They pointed out

\begin{tabular}{|c|c|c|c|}
\hline Industrial Branch & $\begin{array}{l}\text { No. of } \\
\text { Measurements }\end{array}$ & $\begin{array}{l}L_{\text {Aeqr }} \\
d B(A)\end{array}$ & $\begin{array}{l}L_{\text {Cpeak, }} \\
d B(C)\end{array}$ \\
\hline Foundry & 24 & 93 & 127 \\
\hline Plastic packing & 12 & 83 & 112 \\
\hline Metal packing & 22 & 92 & 119 \\
\hline Printing press & 24 & 93 & 119 \\
\hline Shipyard & 28 & 92 & 134 \\
\hline Brewery & 36 & 96 & 117 \\
\hline Porcelain factory & 9 & 88 & 128 \\
\hline Glass factory & 7 & 95 & 113 \\
\hline Glass fibers factory & 3 & 97 & 101 \\
\hline Confectionery factory & 11 & 86 & 106 \\
\hline Weaving factory & 13 & 95 & 119 \\
\hline Stretch factory & 7 & 88 & 114 \\
\hline Paper mill & 21 & 92 & 130 \\
\hline Sawmill & 14 & 84 & 123 \\
\hline Copper tube factory & 5 & 96 & 136 \\
\hline
\end{tabular}


that when the existing criteria were established, the noise-measuring instruments were limited in important ways: linearity of response in terms of level and frequency, the extent of the operating range, directional response, and immunity to the effects of environmental conditions. Many of these shortcomings already have been addressed in contemporary instruments, but additional challenges remain. The workshop participants set out a series of measurement requirements they considered necessary, including linear response from $70 \mathrm{~dB}$ to $170 \mathrm{~dB}$, the ability to capture a waveform with a rise time as short as $5 \mu \mathrm{s}$, and the capability of a sampling rate of $200 \mathrm{kHz}$. Various other features should meet the requirements of IEC 61672-1:2002. ${ }^{92}$ The group also agreed on requirements for noise dosimeters, including a range from $12.5 \mathrm{~Hz}$ to $20 \mathrm{kHz}$; a minimum of A-, C-, and Z- weighting; and the capability of storing several hours of data. Dosimeters should conform at least to the requirements of IEC 61672-1:2002 for class 2.

Through a cooperative research program with Structural Dynalysis Inc., NIOSH has developed and validated a noise measuring system focused on high-intensity impulse sounds. ${ }^{93}$ The purpose of the project was to improve and expand the collection of data on impulsive noise exposures, which in turn could facilitate the development of an agreed-upon damage-risk criterion. The system uses a graphical interface to display seven impulse metrics and three damage-risk criteria: $\mathrm{L}_{\text {Aeq }}$, $\mathrm{AHAAH}$, and MIL-STD-1474D. Among its measurement capabilities are time-domain waveform, frequency spectrum, peak pressure level, $\mathrm{L}_{\mathrm{eq}}$, kurtosis, sample times, number of impulses, and temporal spacing between impulses. The system has been evaluated in the NIOSH noise laboratory using a shock-tube producing impulses from 130 to $170 \mathrm{~dB}$ and in the field at several firing ranges. ${ }^{93}$ Noise measurement systems such as the NIOSH system provide promise for future studies of noise-exposed workers where several important parameters may be examined.

\section{Complex Noise-Animal Experiments}

For many years, investigators have found that noise exposures that include impulse or impact noise produce greater than expected damage to the auditory system, in both animals and humans. ${ }^{8,10,94-96}$ This observation led some to recommend a penalty to the permissible limits for complex noise exposures with a substantial component of impulse/impact noise. Evidence of this appears in Note \#3 of ISO 1999 and Note \#2 of an earlier version, ${ }^{13,20}$ where caution is advised for impulsive or tonal conditions, which could be considered $5 \mathrm{~dB}$ more harmful than broadband, steady, nontonal noise. This note does not appear in the most recent version of ISO $1999 .^{21}$

While studying the effects of complex noise on the chinchilla model, researchers have noted that noise characteristics in addition to overall sound level and peak SPL were important to the effect on hearing and that noise environments with level and temporal characteristics that were non-Gaussian, or not normally distributed, were often more damaging than those that were more evenly distributed. The aspect of peakedness appeared to be fundamental to the outcome, and the kurtosis statistic proved to be a very good descriptor of the resulting hearing damage. ${ }^{10,11,97}$

In these studies of non-Gaussian noise, certain parameters of complex noise were varied, and the effects were compared with predictions on the basis of equal energy. In most cases, the effect of noise exposures involving impulse/impact noise at low to moderate levels have proven to be adequately predicted by $\mathrm{L}_{\mathrm{eq}}$, and at higher levels certain complex noise exposures exhibited more damage than would have been predicted. None of these experiments have shown less hearing loss from complex, non-Gaussian noise exposures, either in terms of PTS or cell loss, than would have been predicted from equal energy.

Several investigations have shown greater hearing damage when impulses or impacts were superimposed on background noise than would have been predicted for either type of noise separately. ${ }^{8-11}$ In an extensive series of experiments to investigate the effects of complex noise, Ahroon et al exposed 23 groups of chinchillas $(n=135)$ for 5 days to octave bands of noise, impact noise alone, or various combinations of impact and octave-band noise, all of equal energy. 9 Their results showed that hearing damage was greater than would have been predicted by equal energy depending on several 
factors: peak SPL, impact repetition rate, presence or absence of background noise, and the frequency component of the background noise. The authors speculated that the $500-\mathrm{Hz}$ octave band would produce more damage than the 4$\mathrm{kHz}$ band because of functional overlap, meaning that the lower frequencies affected the entire audiometric range along the basilar membrane.

\section{Use of Kurtosis}

At this point, it would be useful to examine the concept of kurtosis in more detail.

Kurtosis $(\beta)$ is defined as the ratio of the fourth-order central moment to the squared second-order central moment of a distribution. ${ }^{11}$ It is a measure of the height of the frequency-ofoccurrence histogram, and baseline amplitudes and noise will form the center of the histogram. Sounds having greater excursions, or higher peak amplitudes relative to baseline amplitudes, have greater kurtosis values. Fig. 7 shows a compa- rison of the kurtosis levels of sounds from an impulse noise source with a random noise generated to have the same $\mathrm{L}_{\text {eq. }}$. The kurtosis of the impulse noise is 46.9 , and the kurtosis of the random noise is 3 .

One of the earliest attempts to study nonGaussian noise using kurtosis to assess the effect on hearing of impulses and impacts was proposed by Erdreich, ${ }^{98}$ who pointed out that variables such as repetition rate, spectral content, and multiple peaks occurring before reaching the $-20-\mathrm{dB}$ point with $\mathrm{B}$-duration pulses were not adequately taken into account by equal energy or other existing metrics. The advantage of using kurtosis would be that all peaks would be accounted for as well as the relative difference between peak and background levels.

Many of the most important investigations of hearing damage from complex noise have been conducted over recent years by a team of researchers at the State University of New York (SUNY) in Plattsburgh, New York. ${ }^{9-11,55,97,99-103}$ These investigations

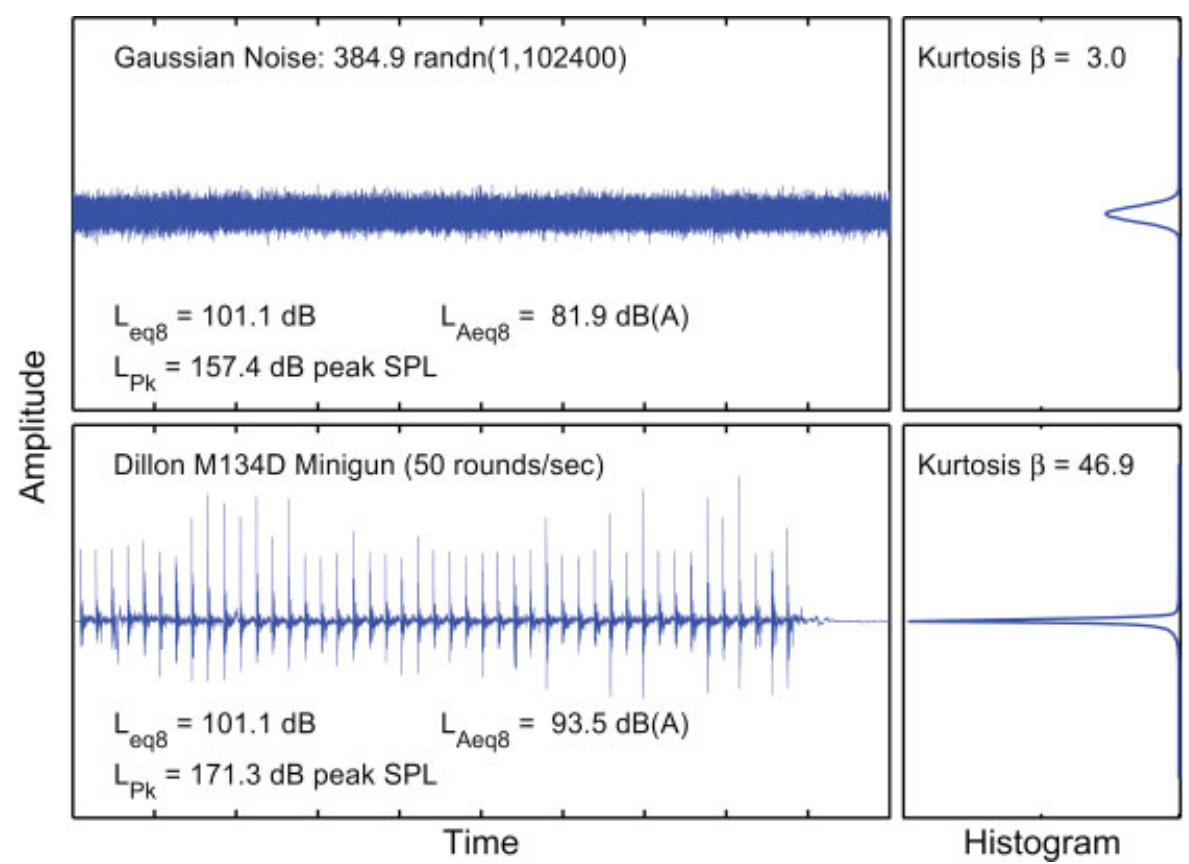

Figure 7 Comparison of histograms from an impulse noise and random noise. The random noise (upper panel) was generated to have the same energy equivalent $\left(L_{e q}\right)$ as the impulse train from a Dillon M134D minigun (lower panel). The amplitude histograms for both waveforms are shown in the panels on the right side of the figure. Minimum and maximum pressures are represented as the tails on the histogram, and the continuous noise embedded in the waveform is represented by the height of the center of the histogram. The kurtosis of the impulse noise is 46.9, and the kurtosis of the random noise is 3 (from Flamme and Murphy; ${ }^{6}$ reprinted with permission). $L_{P k}$, peak level; SPL, sound pressure level. 
measured the effects in terms of TTS, ATS, PTS, and IHC and OHC loss in the chinchilla model. The noise stimulus was varied in terms of overall level, background level, peak level, interpeak interval, intermittency schedule, frequency, and frequency bandwidth. Each experiment involved large numbers of chinchillas, and each study built upon the findings of the previous one, further refining the role of kurtosis and its modifications as a predictive tool.

With a limited set of exposure parameters, Lei et al introduced high-level transients into Gaussian noise and found that the unfiltered kurtosis metric $\beta(t)$ rank ordered the degree of hearing trauma and that the filtered condition of $\beta(f)$ reflected the frequency specificity of the trauma. ${ }^{10}$ Hamernik and Qiu extended the experiment of Lei et al to include more nonGaussian conditions with various peak and background sound levels and broadband noise, all within an overall $\mathrm{L}_{\mathrm{eq}}$ of $100 \mathrm{dBA} .{ }^{11}$ Each non-Gaussian exposure produced more hearing damage than the Gaussian reference exposure. They found that the magnitude of the damage depended not only on the level of kurtosis, but also upon frequency content, with $\mathrm{OHC}$ loss increasing as the stimulus bandwidth increased.

Hamernik et al continued the series by varying the probability of occurrence of the transient and changing the impact interval, peak amplitude, and number of pulses, as well as using an additional range of spectra. ${ }^{97}$ They found that PTS and OHC loss were monotonically related to kurtosis in the range of 3 to 40 ( $\beta=3$ being Gaussian). With $\beta>40$ the degree of trauma appeared to remain constant despite changes in the statistical character of the noise, although later research did not support a plateau. ${ }^{101}$ Impacts with a probability of occurrence of 0.1 were less damaging than those with a higher probability, although they produced more damage than Gaussian noise. In a similar vein, one of their subject groups was exposed to random 100-millisecond noise bursts rather than impacts, which produced greater damage than Gaussian noise but less than the impact stimuli, although the value of kurtosis was the same. The investigators concluded that a correction to the $\mathrm{L}_{\mathrm{eq}}$ for kurtosis should depend on whether the noise consisted of simple noise bursts or impacts. ${ }^{97}$
Further animal investigations by Qiu et al compared $\mathrm{L}_{\mathrm{eq}}$ 90-dBA, 100-dBA, and 110-dBA conditions to those of the earlier experiment by Hamernik et al and introduced additional frequency bandwidths. ${ }^{97,102}$ They found that at 90 $\mathrm{dBA}$, there was no significant difference in response to the Gaussian and non-Gaussian noise conditions, but at higher noise levels differences were apparent. They also found that limiting the stimulus bandwidth reduced the resulting trauma. In these experiments, the animals were exposed to noise continuously for 5 consecutive days. The non-Gaussian transients were band-limited impacts created from $400-\mathrm{Hz}$ bands of noise centered at 1,2 , or $4 \mathrm{kHz}$ or broadband noise. The Gaussian noise was mixed with the impacts to create the non-Gaussian exposures. Although these experiments yielded useful information, they were conducted in conditions that are not typical of most workplaces. The experiments that followed were designed to be more characteristic of workplace exposures.

Hamernik et al extended the previous studies by adding conditions of non-Gaussian interrupted, intermittent, and time-varying noise at energy equivalent levels of $100 \mathrm{dBA}$ or $103 \mathrm{dBA}^{101}$ With a population of 107 chinchillas, they used an interrupted, intermittent, and time-varying schedule to model an industrial work pattern $(8 \mathrm{~h} / \mathrm{d}, 5 \mathrm{~d} / \mathrm{wk}$ for 3 weeks), and continuous Gaussian and nonGaussian noise $24 \mathrm{~h} / \mathrm{d}$ for 5 days for comparison purposes. For the groups exposed to interrupted schedules, the results showed that temporal variations in level (i.e., breaks during the "work shift") had no effect on hearing damage, so long as the $\mathrm{L}_{\text {eq }}$ and kurtosis values were the same. However, increasing the kurtosis at fixed energy levels increased the trauma as earlier investigations had shown. Between $\beta$ values of 3 (Gaussian), 25, and 50, all with the same intermittency schedule, there was a clear ordering of PTS, IHC and OHC cell loss, with $\beta=50$ showing the greatest damage. ${ }^{101}$

In another more recent investigation involving an even larger number of subjects, Qiu et al exposed 225 chinchillas in 29 groups to uninterrupted noise for 5 days or interrupted noise for 19 days, again to model the work week. ${ }^{103}$ There were eight possible combinations of the three 
parameters of interest-impact interval, peak amplitude, and impact duration-which the large size of the subject population enabled the investigators to study independently. In addition to Gaussian noise, subjects were exposed to kurtosis values of 25,50 , or 100 . All exposures were flat-spectrum, broadband noise of equal energy at a level of $97 \mathrm{dBA}$. In the uninterrupted 5-day group, levels of ATS were essentially the same between the groups exposed to Gaussian and non-Gaussian noise and toughening was observed, but there were significant differences in the resulting loss of OHCs and IHCs. In all the non-Gaussian scenarios the results showed a clear ordering of damage with level of kurtosis. For the same spectral energy and fixed values of kurtosis, PTS and cell loss were independent of the temporal structure and peak amplitude of the non-Gaussian noise. Despite the size of this population, there was a very large spread of differences among individuals, with PTS varying from -10 to over $70 \mathrm{~dB}$ and $\mathrm{OHC}$ losses ranging from 0 to $100 \%$. However, organizing the data into groups by kurtosis value made the data set considerably more coherent.

\section{Minimum or No-Added-Effect Level}

There appear to be relatively few studies that use low to moderate levels of both background and impulse/impact noise to assess the level at which kurtosis does not add to the level of damage predicted by equal energy. Some studies suggest that $\mathrm{L}_{\mathrm{eq}}$ is valid for low-level impulses even though it is not sufficiently protective for high-level impulses. ${ }^{59,84,104,105}$ Research by Lataye and Campo suggested support for the equal energy rule for low-level impulse noise, especially in terms of cell damage, but could not claim general validity because they tested only one level of impulse noise $(101 \mathrm{~dB}) .{ }^{47}$ Hamernik et al found that impulse peaks of $103 \mathrm{~dB}$ SPL produced little damage, and there was no evidence of added or synergistic effects when combined with continuous noise at 75 to $85 \mathrm{~dB}$, although the results were mainly stated in terms of TTS. ${ }^{106}$ As mentioned previously, Qiu et al found no significant difference between hearing damage from Gaussian and non-Gaussian noise at $90 \mathrm{dBA}^{102}$ Although these findings do not suggest a specific adjustment to the $3-\mathrm{dB}$
ER for kurtosis or for exposure level, such an adjustment may be forthcoming in future studies.

\section{Summary of Kurtosis Experiments on Animals}

With a total population of more than 800 subjects, these large and detailed animal studies support the value of the kurtosis statistic to assess the hazard of complex noise. They demonstrate increases in PTS and cell loss (both OHCs and IHCs) that are directly related to the level of kurtosis characterizing a signal superimposed on a background noise. The authors identify a range of $\beta=3$ (which they consider Gaussian noise), below which there is no added effect due to kurtosis, up to at least $\beta=100$. Within this range their experiments show that damage in terms of PTS and cell loss in the chinchilla model is monotonically related to the level of kurtosis, beginning at a level of $\sim 90 \mathrm{dBA}$, and, for the conditions evaluated, there is nearly always more hearing damage than would be predicted in Gaussian noise of equivalent energy.

These experiments show that temporal parameters, such as impact duration and interimpact interval, and also peak SPL, are not determinants of damage in conditions of equal energy and kurtosis. Not unexpectedly, as the probability of impact occurrence decreases and the noise condition approaches that of Gaussian or steady-state noise, hearing damage also decreases.

However, these studies reveal certain complexities. As the frequency bandwidth of the noise becomes wider, hearing damage increases. Studying kurtosis of the filtered noise signal could help to identify parts of the cochlea that will be affected. The nature of the stimulus, whether an impact or a short noise burst, can also make a difference, even though the envelope and rise time are incorporated in the kurtosis of the filtered noise signal $\beta(f)$. Although these investigations explored a great number of variables, workplace noise conditions are likely to be even more varied than these.

\section{Complex Noise-Field Studies}

Over recent decades there has been little progress in the conduct of field studies to assess the 
effect of noise on hearing, especially in the United States, since regulations requiring the use of HPDs came into effect in the early 1980s. The use of HPDs will cause actual noise exposures at the level of the tympanic membrane to be changed (usually decreased) by an unknown amount. The same has been true of the nations of the European Community, which have been subject to noise legislation since $1986,{ }^{107,108}$ although the emphasis in Europe has been on engineering noise control rather than hearing protectors. The scarcity of field studies in this area has necessitated reliance on existing data from the 1960s and 1970s.

In a recent review, Dobie and Clark presented an analysis of field studies of intermittent and fluctuating noise from the 1960s and 1970s in an effort to determine the extent to which they supported either a $5-\mathrm{dB}$ or $3-\mathrm{dB}$ ER. ${ }^{109}$ Some of the data they analyzed were part of the original dataset used by Passchier-Vermeer. ${ }^{3}$ However, the authors excluded several of the studies she had selected and added to their analysis other studies from that period. The authors concluded that both the $3-\mathrm{dB}$ and 5-dB ERs overestimated the risk of hearing loss. A subsequent letter pointed out some methodological inconsistencies in their analysis and the likelihood that many of the older studies the authors used lacked important exposure information. ${ }^{110}$ This analysis did draw attention to the weaknesses of some of the older investigations.

On the other hand, there has been controversy for some time about the extent to which the 3-dB ER would be sufficiently protective to assess the effect on hearing of noise environments containing high-level transients like impacts or impulses. Certain investigations during the 1970s and early 1980s found that these environments resulted in greater hearing losses than would be predicted from continuous noise of equivalent energy and recommended a penalty of 5 to $10 \mathrm{~dB}$ for the presence of impulsive components. ${ }^{40,95,111}$ These issues were discussed at an international workshop held at the Institute of Sound and Vibration Research in Southampton, England. ${ }^{112}$ The ensuing consensus report stated that there was not yet clear evidence to separate impulsive and nonimpulsive noise in terms of effect, and the consensus was to accept the A-weighted daily noise exposure on an equal energy basis for all types of noises having different frequency spectra and time functions so long as the unweighted instantaneous peak SPL did not exceed $145 \mathrm{~dB}$. The consensus report recommended field studies on working populations not yet using HPDs and further study on a descriptor of impulsiveness. Although these recommendations were made more than 30 years ago, relatively few of such investigations have been conducted. However, several of the investigations described later have contributed to the knowledge base in this area and show promise of continuing contributions in the future.

\section{Demographic Studies}

In addition to the study referenced above of workers in Hong Kong by Evans and Ming, ${ }^{35}$ other investigations have attempted to shed light on the effects of impact noise on working populations. A study by Taylor et al is an example of the difficulties that can occur when studying hearing loss in a group of workers, many of whom have worn HPDs. ${ }^{113}$ The data from 716 hammer and press operators were originally collected from a drop forge in the United Kingdom between 1970 and 1972. Hammer impacts were measured at peak SPLs of 120 to $140 \mathrm{~dB}$ and occasionally above, and the workers' 8-hour $\mathrm{L}_{\mathrm{eq}}$ was estimated at 108 dBA. Their HTLs were compared with those of press operators exposed to slightly lower impact levels (110 to $120 \mathrm{~dB}$ SPL), with an estimated $\mathrm{L}_{\mathrm{eq}}$ of $99 \mathrm{dBA}$. The exposure schedule was 40 minutes on and 20 minutes off with a 30-minute lunch break. Background levels were measured at 10 to $15 \mathrm{~dB}$ below the ontime levels. HPDs had been worn by $61 \%$ of the workers for durations of between 1 and 4 years. Noise exposure durations were calculated by subtracting the number of years wearing HPDs from the total duration.

The results of the study by Taylor et al showed that both groups had substantially more hearing loss than a non-exposed control group, especially in the 45 to 55 age range, but they also showed that hearing losses among the two groups were significantly affected by age and exposure duration. ${ }^{113}$ Among the younger workers, even though the exposure level of 
the hammer operators was considerably higher than the press operators $\left(\mathrm{L}_{\mathrm{eq}}\right.$ of 108 versus 99 $\mathrm{dBA}$ ), their HTLs were about the same, and one might conclude that higher peak SPLs and increased energy caused less damage. The result was the opposite for workers whose exposure exceeded 10 years, where increased impact level and energy produced considerably more hearing loss in the hammer operators, although the HTLs of the two groups were similar at $4 \mathrm{kHz}$ and $6 \mathrm{kHz}$. When these subjects' HTLs were compared to those that would be predicted for equivalent exposures by the method of Robinson (i.e., Burns and Robinson-one of the methods referenced in the ISO 1999 standard $^{33}$ ), those between ages 15 and 24 showed less or equal amounts of loss, whereas those between ages 35 and 54 showed more loss than would be predicted. The authors suggest that impact noise in general has a very similar effect on the hearing mechanism for exposures of less than 10 years, but for longterm exposures a latent effect becomes manifest. Unfortunately, the relative history of HPD use between the two groups is not discussed, and it is possible that the younger workers were more inclined to wear hearing protectors.

Research on the hearing of sheet metal workers in a French automobile manufacturing plant has provided additional information on this issue. ${ }^{96}$ A group of 234 workers engaged in activities such as welding, brazing, hammering, and sanding was screened for a variety of nonoccupational factors and for any regular wearing of HPDs. Workers were exposed to moderate levels of complex noise with an $\mathrm{L}_{\mathrm{eq}}$ of 87 to $90 \mathrm{dBA}$. Their HTLs were compared with two other populations where the audiometric data were collected and analyzed in a similar manner. One of the comparison groups was exposed to workplace noise levels no greater than $80 \mathrm{dBA}$, and the other to continuous noise of $95 \mathrm{dBA}$. In the study population the median difference between peak and $\mathrm{L}_{\mathrm{eq}}$ values was $\sim 27 \mathrm{~dB}$. The results showed HTLs for the group exposed to complex noise to be comparable to the continuous noise group at $95 \mathrm{dBA}$. The authors also compared their findings to predictions using ISO 1999 with similar results, concluding that the $\mathrm{L}_{\mathrm{eq}}$ metric underestimated the damage found in this type of noise-exposed population.
Demographic studies of workers conducted by researchers at the University of Washington have explored alternative noise exposure metrics and hearing loss among construction workers. ${ }^{114,115}$ In an attempt to find the best metric for conditions that include highlevel noise events, the authors examined a large database of workers exposed to the complex noise environments typical of construction. They compared several noise metrics over a variety of tasks, including 360 work shifts in nine trades. The metrics they examined were the $\mathrm{L}_{\text {avg }}$ (representing the 5-dB ER), the $\mathrm{L}_{\text {eq }}$ (3-dB ER), and the $L_{\max }$ (in the fast response mode) to describe the highest maximum level measured during a specific period. In the earlier of the two studies, the authors presented two novel exposure metrics: $\mathrm{L}_{\mathrm{avg}} / \mathrm{L}_{\mathrm{eq}}$ to address variability over time by revealing the difference between the 5-dB and 3-dB ERs and $\mathrm{L}_{\max } /$ $\mathrm{L}_{\mathrm{eq}}$ to describe noise environments with highlevel transients. ${ }^{114}$ They also referred to the possibility of using kurtosis for this purpose, but considered this metric impractical for realworld use.

In a follow-up study, Seixas et al examined hearing loss data from construction apprentices over a 10-year period, in the form of distortion product otoacoustic emissions (DPOAEs) as well as pure-tone audiometry. ${ }^{115}$ The study took place in two 5-year phases. The subject base consisted of 316 apprentices after excluding $\sim 30 \%$ of the initial cohort for various reasons. Baseline HTLs in these new workers from previous exposures (occupational and recreational) were somewhat greater than expected. Exposure was assessed in a task-based method where the amount of exposure time was summed across all jobs within a specific interval, and nonoccupational noise exposure was also factored in to arrive at a total annual 2,000-hour equivalent noise exposure. To test the additional effect of peakiness (peakedness) they used the $\mathrm{L}_{\max } / \mathrm{L}_{\text {eq }}$ metric developed previously, which they divided into two categories: $\mathrm{L}_{\max } / \mathrm{L}_{\mathrm{eq}}$ less than or greater than 50 . The results of the peakedness test were inconclusive between phases 1 and 2 and between the DPOAE and pure-tone methods. The investigators concluded that the modest increases in HTL over the study period were as great as or 
greater than those that would be predicted using the ISO model for NIHL.

These investigations demonstrate the difficulties inherent in large-scale demographic studies of noise exposure among workers, especially longitudinal studies. Variability of noise exposure profiles is particularly great among construction workers where intermittencies and impacts are common and there is considerable worker mobility. The authors point to the challenges due to changes in protocols during the 10-year period and the fact that many of the apprentices had previously worked in construction more than 2 years and had nonoccupational exposures as well. Their average HTLs at $4 \mathrm{kHz}$ were $7 \mathrm{~dB}$ higher than those of the control group. Some had worn HPDs, although there were only negligible differences in effects between self-reported HPD use and those who never wore them.

\section{Studies of Chinese Workers}

In an effort to initiate the development of doseresponse criteria for industrial noise populations exposed to complex noise environments, a team of U.S. and Chinese researchers studied groups of Chinese workers who used HPDs minimally or not at all. The object of these investigations was to examine the ability of the kurtosis metric, whose importance has been shown in several of the animal studies described previously, to differentiate between hearing loss due to Gaussian and non-Gaussian noise conditions.

In the first of these experiments, Zhao et al compared hearing loss data from 32 subjects exposed to non-Gaussian noise in a metal fabrication plant to the data from 163 subjects exposed to Gaussian noise in a textile mill, controlling for exposure duration and excluding subjects with nonoccupational factors such as military service. ${ }^{116}$ Noise exposure or dose was stated in terms of cumulative noise exposure (CNE) levels, based on the A-weighted $\mathrm{L}_{\text {eq }}$ normalized to an 8-hour day, occurring over time intervals in terms of years. CNE levels were 110.6 dBA for the Gaussian noise exposures and 103.2 dBA for the non-Gaussian noise. Continuous noise exposure levels in the textile plants ranged from 96 to $105 \mathrm{dBA}$, and the complex noise in the metal fabrication plan contained peak SPLs up to $125 \mathrm{~dB}$. The investigators used the kurtosis statistic to quantify the deviation of the non-Gaussian from the Gaussian noise environments. The results are stated in terms of the prevalence of age-adjusted high-frequency noise-induced hearing loss defined as one or more HTL at 3,4 , or $6 \mathrm{kHz}$ in either ear $\geq 30 \mathrm{~dB}$.

Fig. 8 from Zhao et al shows a significant difference in high-frequency hearing loss between the Gaussian and non-Gaussian groups. ${ }^{116}$

Fig. 9, from the same study, shows that when the CNEs were adjusted for kurtosis, the two curves overlapped. ${ }^{116}$ These results confirmed the previous findings from several animal experiments (described above) that exposures characterized by impulses or impacts superimposed onto continuous or varying noise are more damaging than continuous noise alone. They also suggested that the kurtosis metric would be a reasonable candidate for modifying the $\mathrm{L}_{\mathrm{eq}}$ in the presence of complex noise exposures.

Extending this type of investigation further, the U.S.-China team selected a subject base of 240 workers, rigorously screened to exclude non-noise and nonoccupational hearing loss, 207 of whom were exposed to non-Gaussian noise and 33 to Gaussian noise environments. ${ }^{117}$ Median NIPTS for the nonGaussian population was significantly greater than would be predicted by ISO 1999. The investigators' use of ISO's Annex B may have been problematic in that they compared their subjects' binaural average HTLs with the better-ear values of Annex B. However, these differences could be more than offset by the fact that the Chinese population was heavily screened and Annex B reflects HTLs of an unscreened population.

The Chinese worker groups were divided into three exposure ranges: 85 to $88 ; 88$ to 91 , and 91 to $94 \mathrm{dBA}$; two durations, less than or more than 10 years; and two levels of kurtosis: $\beta<10$ or $\beta>10$. The results showed that the median NIPTS increased by an average of $3 \mathrm{~dB}$ as median kurtosis level increased from $\beta(t)$ $\leq 10$ to $>10$. The mean NIPTS increased by $8.1 \mathrm{~dB}$ as the mean kurtosis level increased from $\beta(t) \leq 10$ to $>10$. This effect was consistent 


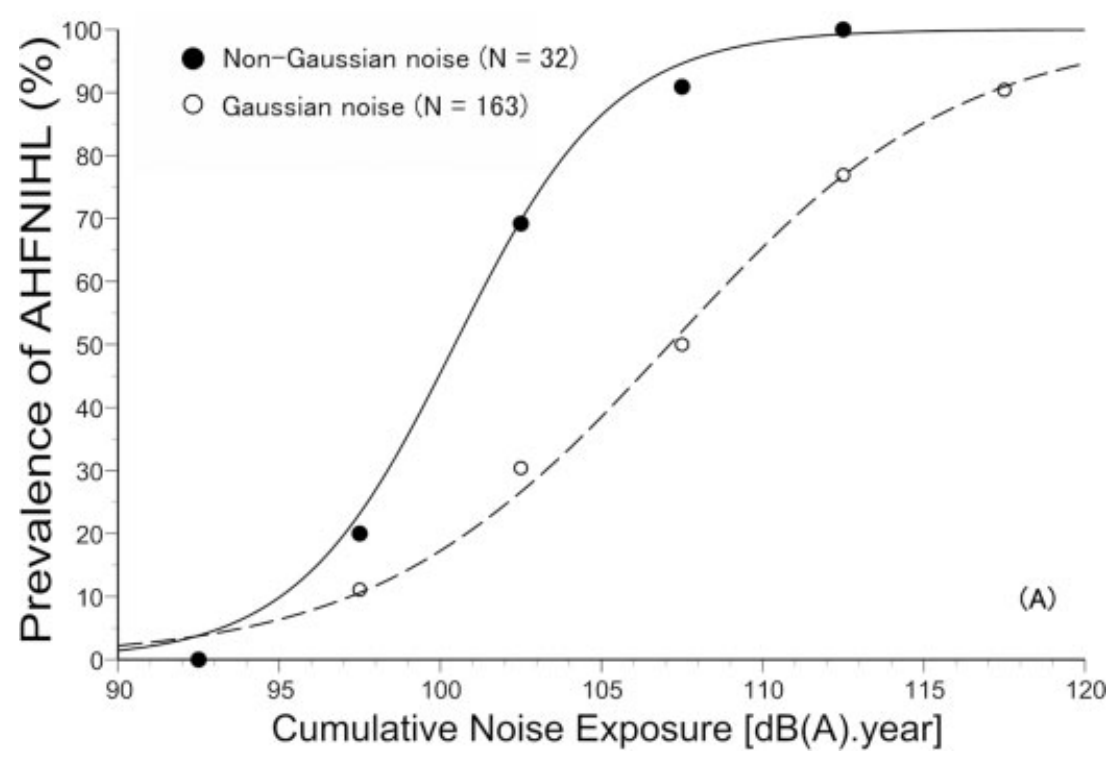

Figure 8 Prevalence of age-adjusted high-frequency noise-induced hearing loss (AHFNIHL) as a function of cumulative noise exposure for workers exposed to complex noise versus Gaussian noise (from Zhao et al; ${ }^{116}$ reprinted with permission).

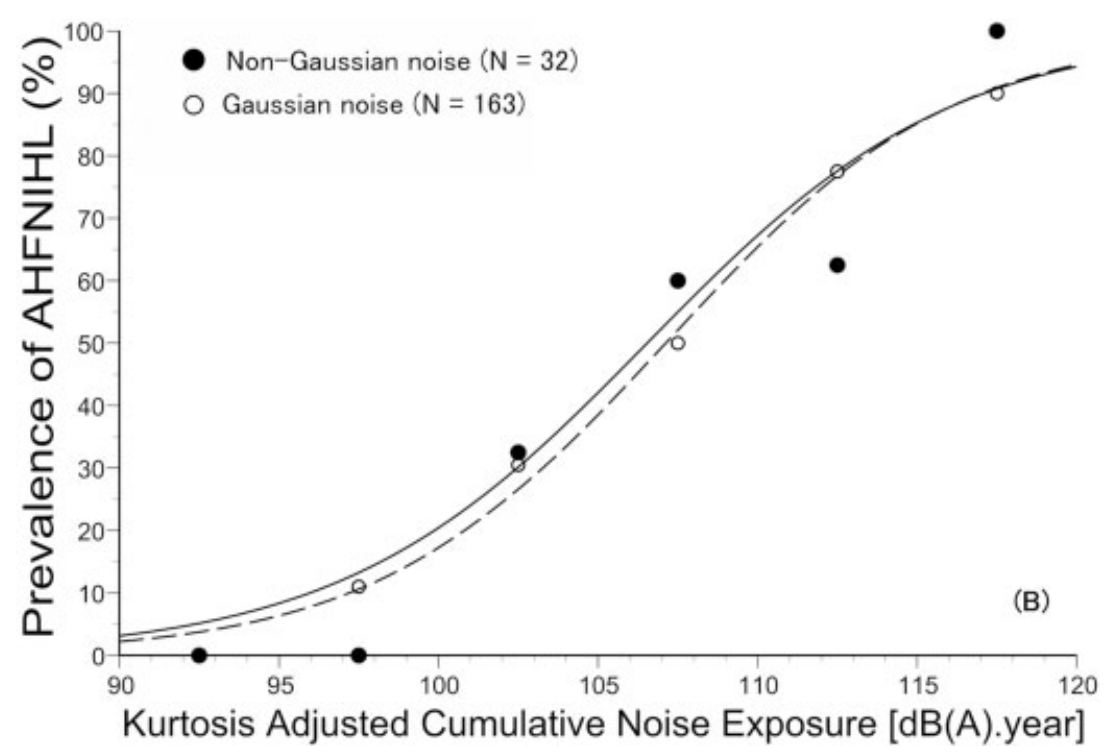

Figure 9 Prevalence of age-adjusted high-frequency noise-induced hearing loss (AHFNIHL) as a function of cumulative noise exposure (CNE) for workers exposed to complex noise versus Gaussian noise when the CNEs have been adjusted for kurtosis (from Zhao et al; ${ }^{116}$ reprinted with permission).

across test frequencies and among exposure levels. The investigators conclude that the kurtosis metric is important to the determination of hearing hazard from complex industrial noise exposures.
The third study by the U.S.-China team used a larger subject base $(n=341)$ and two different non-Gaussian work environments, a steel rolling mill (132 subjects), and a manufacturing plant (46 subjects) in addition to 
subjects exposed to Gaussian noise from a textile plant (163 subjects). ${ }^{118}$ Strict exclusion criteria were applied again as well as the same CNE method, with and without an adjustment for kurtosis. According to the authors, the equation for $\mathrm{CNE}$ simplified for a single noise environment is:

$$
\mathrm{CNE}=L_{\text {Aeq,8h }}+10 \log (T)
$$

Modified to include kurtosis it is:

$$
\mathrm{CNE}^{\prime}=L_{A e q, 8 h}+\frac{\ln (\beta)+1.9}{\log (2)} \log (T)
$$

NIPTS was calculated by subtracting median HTLs for comparable age and gender groups from the non-noise-exposed population in ISO 1999 Annex $A,{ }^{20}$ which was assumed to be similarly screened. The results showed that hearing loss in the non-Gaussian groups was significantly worse than in the Gaussian group exposed to textile noise. There was a considerable amount of individual variability, consistent with earlier experiments. The model adjusted for kurtosis showed a modest increase in the amount of variability explained, indicating that adding kurtosis to the CNE improved the accuracy of the hearing loss predictions. Once again, the authors suggest that any method of predicting hearing damage from complex noise should be adjusted for kurtosis.

In an attempt to relate the results of the SUNY chinchilla experiments to the recent data by Zhao et al on Chinese workers exposed to complex noise, ${ }^{116}$ Goley et al correlated various noise metrics with NIHL defined as average PTS for the frequencies $0.5,1,2$, and $4 \mathrm{kHz}{ }^{119}$ They found that adding a correction for kurtosis improved the correlation of the various formulas with NIHL, but they observed that the efficacy of these kurtosis-adjusted formulas is based on the assumption that Gaussian noise, with a kurtosis of 3 , is the reference noise exposure. They also pointed out that our existing damage-risk criteria are based on what was considered "common" occupational noise exposures, and therefore the assumption of $\beta=3$ may not be universally applicable. If these historical data included "continuous" noise exposures with higher values of kurtosis, then the risk of exposure to complex noise could be overestimated. This possibility would provide another reason for validation with human data, to the extent possible, comparing noise-exposed populations with one another rather than to predictions using ISO $1999 .^{21}$

\section{NEUROLOGIC INVESTIGATIONS OF THE AUDITORY SYSTEM}

Learning Outcomes: As a result of this activity, the participant will be able to define synaptopathy and describe the recent evidence related to noise exposure on neurologic components of the auditory system.

The field of hearing science has been augmented over recent years with research on the effects of noise exposure on neurologic components and processes in addition to cochlear structures like OHCs and IHCs. Over the past several years, research employing improved microscopy and staining techniques has enabled investigators to concentrate on ever more intricate changes associated with noise exposure. Findings from these studies call into serious question the adequacy of previous criteria based on assumptions such as the following:

- Hearing damage is best reflected by either PTS or hair cell loss or a combination of the two.

- Damage to hearing stops with the cessation of noise exposure.

- Noise exposures that do not affect a person's HTLs have no impact on the way a person perceives or understands suprathreshold signals.

- The processes of noise-induced hearing loss and presbycusis are independent.

The hearing loss research community has long embraced these assumptions, which were important to the selection of the $5-\mathrm{dB}$ ER by OSHA many years ago.

A recent conference took place at the National Institute on Deafness and Other Communication Disorders (NIDCD) entitled "Synaptopathy and Noise Induced Hearing Loss: Animal Studies and Implications for 
Human Hearing." ${ }^{" 120}$ Fourteen auditory scientists from the United States and abroad shared their research and participated in the discussion. Impetus for the workshop was provided by the increasing number of animal studies revealing substantial irreversible neural degeneration following TTS, despite apparent recovery of threshold sensitivity and lack of hair cell loss. Several of these studies have demonstrated extensive loss of synaptic connections between hair cells and auditory nerve terminals, resulting in subsequent degeneration of spiral ganglion cells and their central projections. ${ }^{121-126}$

Researchers in hearing science have known for decades that persons with mild hearing losses or even audiograms considered normal can have disproportionate and unexplained difficulties with suprathreshold stimuli, particularly with understanding speech in a background of noise. ${ }^{127-130}$ Groundbreaking research by Kujawa, Liberman, and their colleagues at the Harvard Medical School and the Massachusetts Eye and Ear Infirmary, as well as several other investigators, has led to explanations for this phenomenon, particularly when it involves noise exposure. $^{121-126,129,131}$ The explanation lies in the relationship of the IHCs to the neurons of the spiral ganglia by way of their synapses. The term synaptopathy as applied to the ear has come to represent a disorder due to noise, aging, or genetic conditions that causes losses of spiral ganglion neurons and their synapses, and yet can leave little or no effect on HTLs. These synaptic ribbons and the neurons with which they communicate are highly specialized to enable "indefatigable sound encoding with the utmost temporal precision." ${ }^{131}$ Their dysfunction, known as cochlear synaptopathy, affects suprathreshold perceptions that are vital to the comprehension of speech.

According to Spoendlin, ${ }^{132}$ 95\% of the auditory nerve fibers that connect the cochlea with the brain contact IHCs only, not OHCs or other cochlear structures. IHCs form between 15 and 20 ribbon synapses with the peripheral axons of spiral ganglion neurons in what Moser et al admiringly call "multiprotein nanomachinery."131(p.996) Damage to the OHCs, which until recently has been the primary focus of experimental attention, causes loss of cochlear amplification reflected as reduced threshold sensitivity assessed by pure tone audiometry, otoacoustic emissions, or neural responses by auditory brainstem response (ABR). By contrast, cochlear synaptopathy is just as likely to coexist with normal audiometric thresholds, otoacoustic emissions, and ABR wave $\mathrm{V}$ amplitudes. However, synaptopathy may manifest in abnormalities in the amplitude of ABR wave I. ${ }^{124}$ Animal research points toward auditory synaptopathy as responsible for disrupting the encoding of suprathreshold sound signals. These suprathreshold effects have been known for some time as "hidden hearing loss" because they hide behind a normal audiogram. They are now increasingly being identified with the results of research in noise-induced cochlear synaptopathy. ${ }^{133}$

Animal experiments have shown that noise exposure, regardless of whether it results in TTS or PTS, produces swelling in the IHC area thought to be due to glutamate excitotoxicity. Although the swelling seen immediately postexposure soon disappears and there is recovery from TTS, complete neural recovery does not occur. Using the mouse model, Kujawa and Liberman found 40 to $50 \%$ loss in the number of synapses between IHCs and auditory nerve fibers with no loss of IHCs or OHCs and complete recovery of auditory thresholds. ${ }^{122}$ Adverse effects on the spiral ganglia occurred more slowly, but over a period of 1 to 2 years, loss of spiral ganglion cells eventually matched the acute loss of synapses. To date, noiseinduced synaptopathy has been documented in several mammalian species suggesting that it is likely to occur in humans as well.

Kujawa and Liberman address the reasons the adverse effects of auditory synaptopathy have remained hidden for so long: (1) spiral ganglion cells can survive for years despite the loss of their connection with hair cells, (2) the synaptic terminals of these nerve fibers are unmyelinated and are therefore difficult to see with traditional microscopy and staining techniques, and (3) neuronal degeneration is selective for cochlear nerve fibers with high thresholds. ${ }^{123}$

Recent developments in the use of highpower confocal microscopy and immunostaining techniques have enabled researchers to view and quantify changes to IHC and spiral ganglion neuron synapses much more 


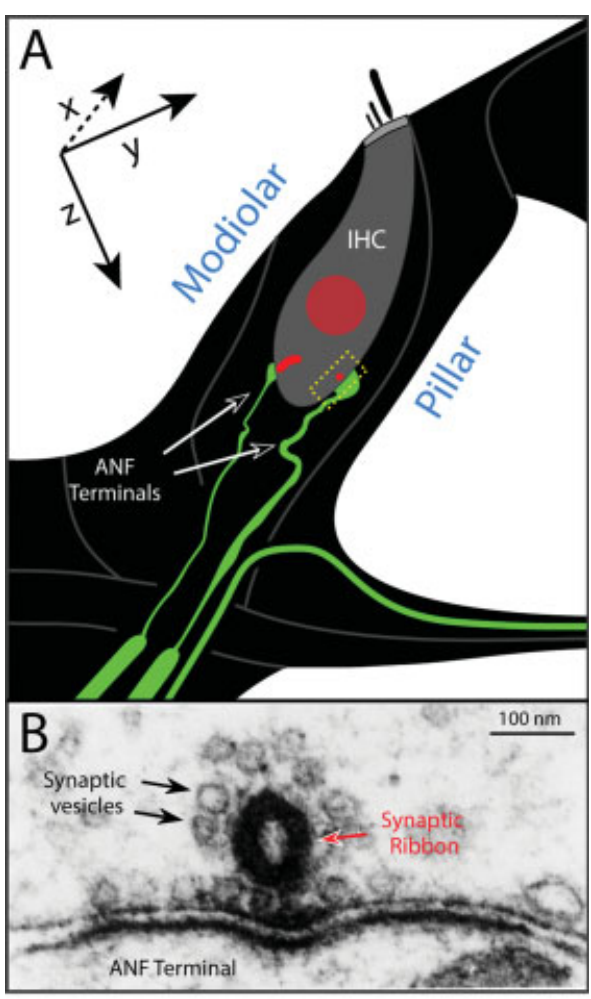

Figure 10 (A) Schematic showing two of the 15 to 20 nerve terminals making synaptic contact with a single inner hair cell (IHC). (B) Electron micrograph of a synaptic complex within the IHC (depicted in the dotted rectangle in A) showing cross section of the synaptic ribbon with a halo of synaptic vesicles (from Lin et al $^{124}$ reprinted with permission). ANF, auditory nerve fiber terminal.

effectively than in the past. Fig. 10 from Lin et al shows a schematic of an IHC with two of the 15 to 20 nerve terminals making synaptic contact. ${ }^{124}$ The electron micrograph in Fig. 10 shows a cross section of the synaptic ribbon with a halo of synaptic vesicles within the IHC.

Fig. 11, also from Lin et $\mathrm{al}^{124}$ shows an example of synaptic ribbon loss in guinea pigs exposed to $106 \mathrm{~dB}$ octave-band noise 10 days postexposure. In contrast to the unexposed subjects in Fig. 11A, one can see loss, disorganization, and dysmorphology of synaptic ribbons in Fig. 11B.

Fig. 12 from the same experiment shows ABR thresholds and DPOAE levels 10 days postexposure. Despite considerable amounts of
TTS, ABR thresholds and DPOAEs have returned to pre-exposure levels.

In Fig. 13, however, ABR wave I amplitude is significantly reduced 14 days postexposure, particularly at the higher stimulus levels, indicative of synaptopathy.

The question arises as to how there can be so much damage to auditory synapses and yet subjects present with normal HTLs. Kujawa and Liberman point out that the insensitivity of the pure-tone audiogram to diffuse neural degeneration has been well known for many years and that only a small number of auditory nerve fibers along the basilar membrane are necessary to detect a pure-tone stimulus in quiet. ${ }^{123}$ Both noise and aging tend to decrease the number of synapses of nerve fibers with high thresholds, which would imply that existing low-threshold fibers would continue to respond to low-intensity auditory signals. In addition, noise and aging are likely to affect auditory nerve fibers with low spontaneous discharge rates, ${ }^{125}$ which tend to have large dynamic ranges and reduced susceptibility to masking by continuous noise. ${ }^{134,135}$ The loss of nerve fibers with large dynamic ranges and properties that protect against masking would necessarily lead to difficulties in understanding complex stimuli in noisy environments. In this way, the concept of cochlear synaptopathy helps to explain the old question as to why certain noise-exposed or aging individuals whose audiograms show essentially normal hearing or only mild losses have disproportionately serious difficulties understanding speech in noise.

In addition to the importance of healthy spiral ganglion neurons and synaptic connections to the IHCs, Fernandez et al have presented evidence questioning the long-held assumption about the independence of noise and aging. ${ }^{126}$ It appears that the deterioration set in motion by synaptopathy interacts with the aging process to exacerbate presbycusis. Using the mouse model, the authors compared two exposures. One was purposely chosen to produce mild TTS but no loss of synapses, a 2-hour octave-band ( 8 to $16 \mathrm{kHz}$ ) exposure at $91 \mathrm{~dB}$. The other exposure, the same noise band for 2 hours, was presented at $100 \mathrm{dBA}$ and resulted in both TTS and acute synaptic loss. These exposed animals, plus a group of unexposed controls, 


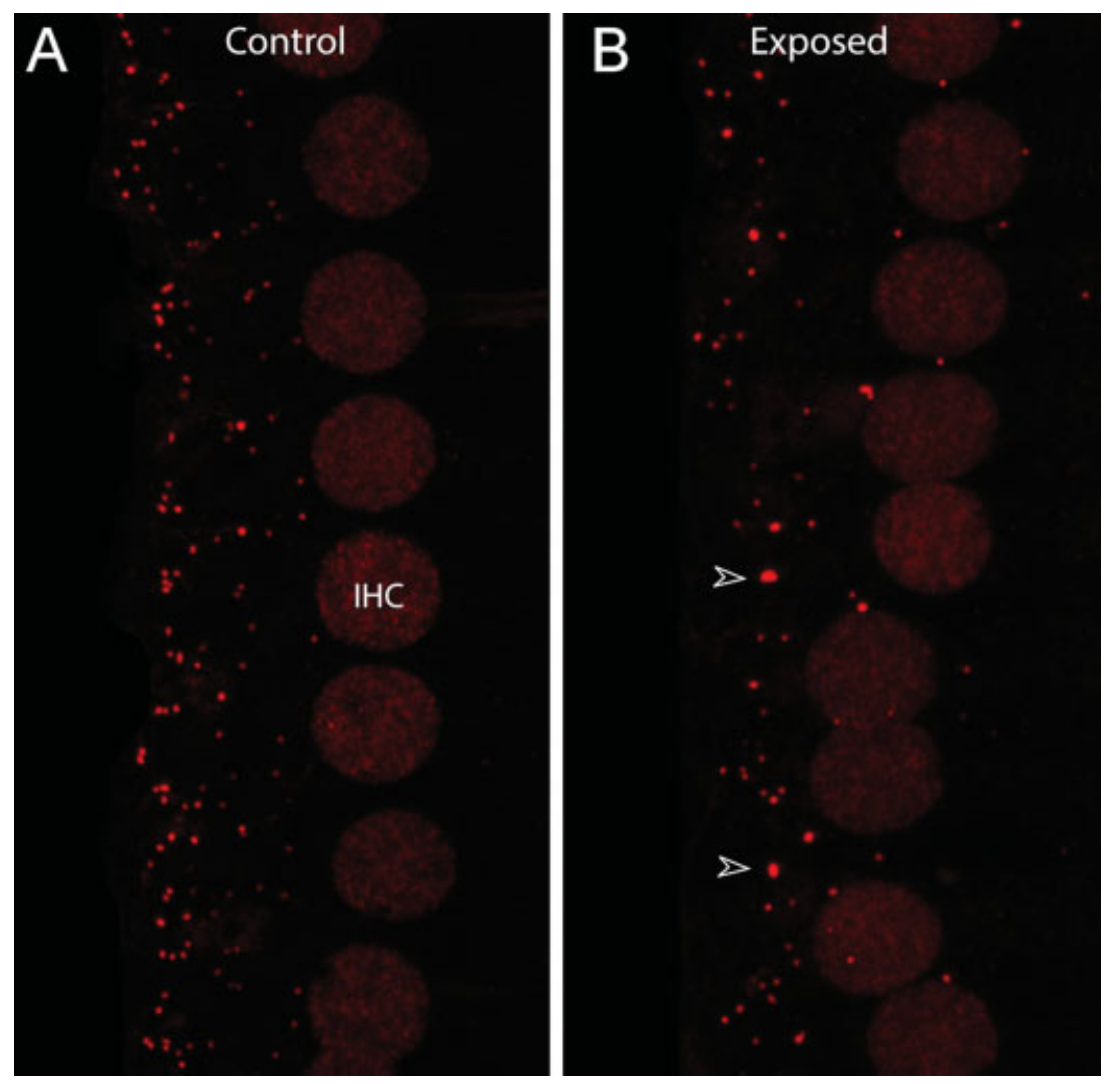

Figure 11 Confocal images of the inner hair cell $(\mathrm{IHC})$ area in control $(\mathrm{A})$ and noise-exposed $(\mathrm{B})$ guinea pigs, immunostained for synaptic ribbons. (B) Loss and disorganization of synaptic ribbons, with arrows pointing to abnormally large ribbons (from Lin et $\mathrm{al}^{124}$ reprinted with permission).

were followed for up to 88 weeks as they aged. The low-level exposure group exhibited mild TTS (30 to $35 \mathrm{~dB}$ ) but no loss of synapses, whereas the 100-dB group showed an immediate loss of synaptic count that progressed with age. These losses initially occurred in the cochlear base, and with aging spread toward the cochlear apex in a greater decline than that exhibited by the unexposed or low-noise groups. $\mathrm{OHC}$ and spiral ganglion neuron losses in the low-noise, 91- $\mathrm{dB}$ group occurred at the same rate as in the unexposed subjects.

Fig. 14 from Fernandez et al shows the differences between threshold shifts in the synaptopathic (100-dB) noise-exposed group compared with the unexposed subjects as the two groups age. ${ }^{126}$ Although both DPOAE and $\mathrm{ABR}$ thresholds are similar through $\sim 32$ weeks, there is a significant difference by week 64. At least two caveats emerge from these results. First, not all TTS exposures result in synaptopathy, which is fortunate. But not so fortunate is that early noise exposure sufficient to damage cochlear synapses appears to exacerbate the hearing degradation typical of aging. In other words, presbycusis is not independent of the adverse effects of noise. These results would support the demographic studies of Gates et al and Rosenhall, ${ }^{136,137}$ which indicate age-noise interactions.

In a review of the perceptual consequences of cochlear neuropathy, Plack et al pointed out that "hidden" hearing loss in humans has been observed for many years and that some of these cases may actually have had $\mathrm{OHC}$ dysfunction because the categorization of "normal" hearing can cover a range as large as $30 \mathrm{~dB}$ at some frequencies. ${ }^{129}$ The authors review several studies showing poor performance on various kinds of suprathreshold tests by noise-exposed 

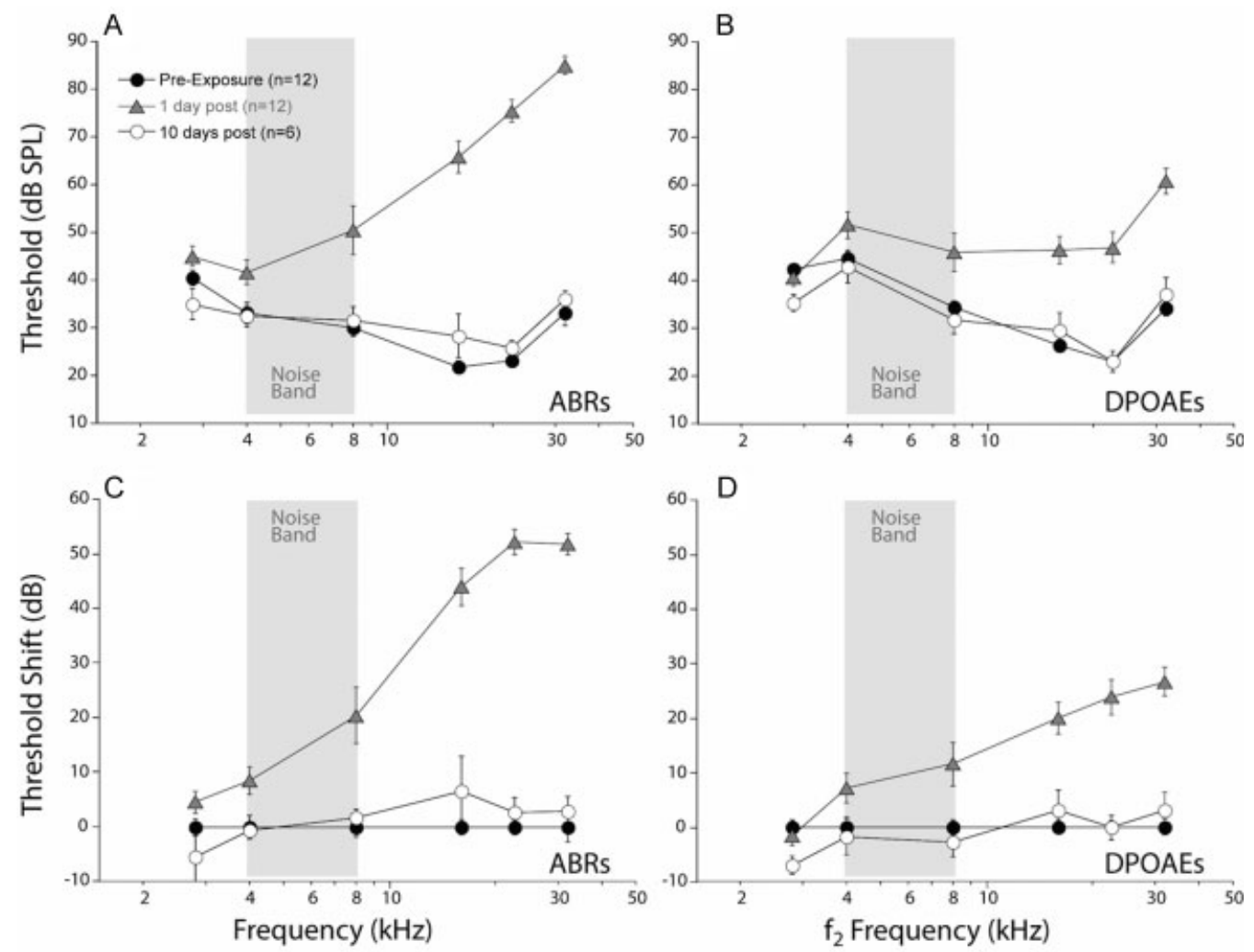

Figure 12 Auditory brainstem response (ABR) and distortion product otoacoustic emission (DPOAE) levels as a function of audiometric frequency in noise-exposed guinea pigs. Thresholds are shown as hearing threshold levels in $A$ and $B$ and threshold shifts in $C$ and D. Despite large initial threshold shifts, ABR and DPOAE thresholds have recovered by 10 days postexposure (from Lin et $\mathrm{al}^{124}$ ). SPL, sound pressure level.

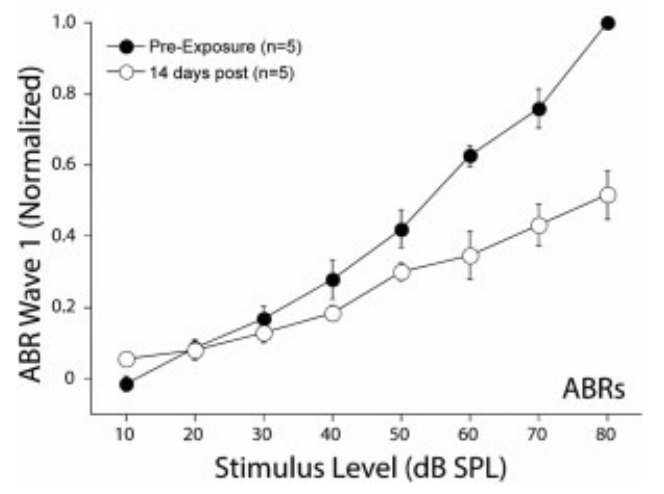

Figure 13 Normalized auditory brainstem response (ABR) wave I as a function of stimulus level in guinea pigs 14 days postexposure, showing significant reduction compared with pre-exposure levels (from Lin et $a_{l}{ }^{124}$ reprinted with permission). SPL, sound pressure level. individuals compared with those without a history of noise exposure, both groups having normal or similar HTLs. Although these investigations are indicative of cochlear neuropathy, they suffer from problems such as adequate matching of HTLs among groups, small numbers of subjects, and the possibility of hearing sensitivity that is not actually normal. The authors conclude that an explanation of cochlear neuropathy or hidden hearing loss in humans is not yet definitive and may be caused by a diverse set of pathologies. However, they maintain that the connection is stronger for tinnitus, citing reduction of $A B R$ wave I at high levels among subjects with normal HTLs experiencing tinnitus. ${ }^{138}$ Kujawa and Liberman provide further support for the relationship between noise exposure without PTS and both tinnitus and hyperacusis, ${ }^{123}$ citing research by Roberts et al and Hickox and Liberman. ${ }^{139,140}$ 


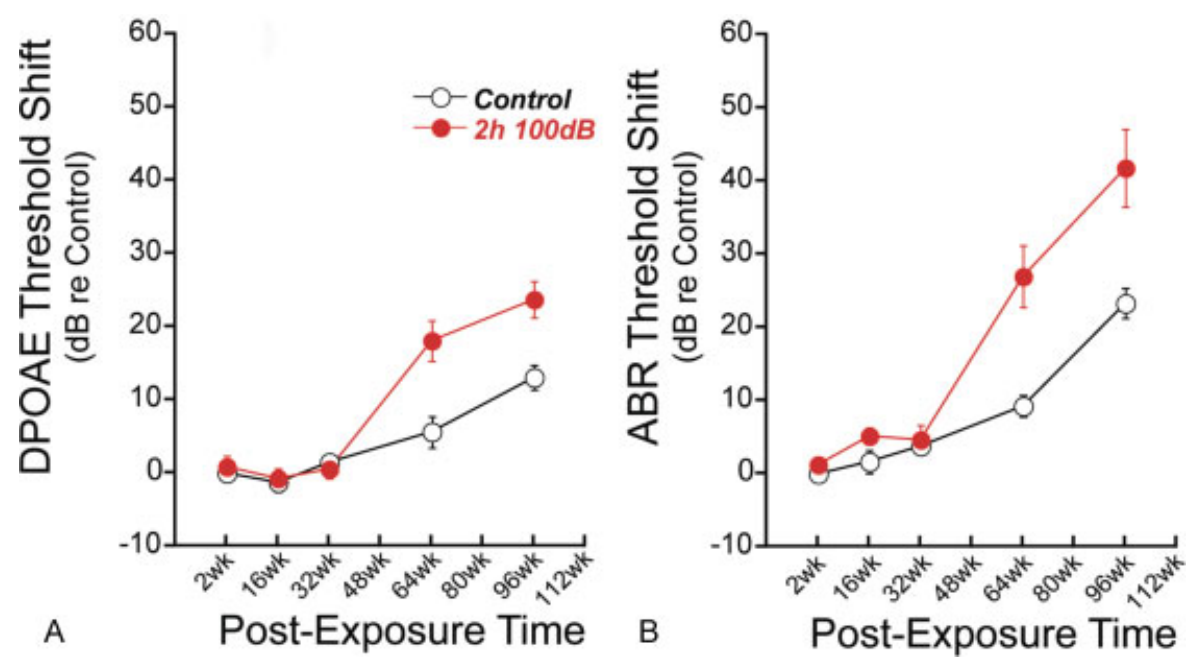

Figure 14 Threshold shifts in mice for the 32-kHz frequency shown as distortion product otoacoustic emissions (DPOAEs) and auditory brainstem response (ABR) thresholds as a function of postexposure time. Animals exposed for 2 hours at $100 \mathrm{~dB}$ are compared with unexposed subjects as both groups age. Although thresholds for both groups are similar up to 32 weeks, there are significant differences at 64 weeks and after (from Fernandez et al; ${ }^{126}$ reprinted with permission).

A recent study of human subjects with HTLs carefully defined as normal provides further evidence that threshold testing is not necessarily the "gold standard." ${ }^{141}$ Investigators tested cochlear function in 26 subjects with HTLs no greater than $15 \mathrm{~dB}$ at the frequencies between 250 and $8 \mathrm{kHz}$, using DPOAEs and several suprathreshold measures, such as frequency selectivity, amplitude modulation, temporal coding, and several others. Even among these subjects with normal HTLs, they found large individual differences in perceptual abilities, and they found that measures of cochlear function accounted for very little of the variability in such tests as attention task performance and suprathreshold temporal coding. They concluded that individual differences in normal-hearing listeners are driven by differences originating early in the neural portions of the auditory pathway, differences that are not related to mechanical transduction, and, once again, that the audiogram is an insensitive determinant of hearing ability. They also suggest that noiseinduced neuropathy would be a significant contributor to what is thought to be "normal" variability in the perception of complex sounds.

Recent investigations of human temporal bones using efficient new immunostaining procedures have helped clarify these relationships in humans. In an examination of human temporal bones from ears with no significant loss of hair cells, Makary et al nevertheless found progressive declines in spiral ganglion counts, and they found that ears with a history of noise exposure could show exaggerated reductions. ${ }^{142}$ Viana et al examined temporal bones from elderly subjects and found spiral ganglion cells surviving in much greater numbers than their peripheral axons, indicating the probability of functional neuropathy despite the absence of otologic abnormalities or significant hair cell loss. ${ }^{143}$ They concluded that the evaluation of spiral ganglion cell death greatly underestimates the possibility of neural presbycusis in humans. This observation should apply to noise-induced synaptopathy as well.

To summarize the findings of these investigations related to the neurologic effects of noise, it appears that noise exposure levels previously considered benign are not without adverse effects. Although this discussion may not seem directly related to the issue of the ER, it calls into question any criteria based on the assumptions listed previously. Consequently, hearing damage is not reflected only by PTS or cell loss; damage to hearing appears to continue after the cessation of noise exposure; normal HTLs do not signify an absence of damage to the 
auditory system; suprathreshold signals may be adversely affected without PTS or cell loss; and the mechanisms of noise-induced hearing loss and aging are not independent of one another, but that noise exposure appears to exacerbate the effects of aging. Although these kinds of auditory damage may not manifest as pure-tone threshold decrements, nevertheless they point to suprathreshold difficulties characteristic of "hidden hearing loss," as well as problems with hearing sensitivity in the future.

According to Moser et $\mathrm{al}^{131}$ :

The extent, irreversibility, and functional consequences of excitotoxic synapse loss ... now require studies of the relevance of this disease mechanism for human noise-induced hearing loss. If comparable to the animal findings, which is likely the case, noise exposure is much more dangerous than we have assumed. We will then have to acknowledge that noise induces synapse and progressive neuron loss and thereby impairs speech reception in noisy environments. We will need to revise noise exposure guidelines, diagnostic procedures and clinical evaluation of occupational hearing loss. ${ }^{131(\mathrm{p} .1001)}$

\section{SUMMARY AND CONCLUSIONS}

Many of the TTS studies on which earlier damage-risk criteria were based are no longer appropriate for that purpose, which was stressed in the earlier report. ${ }^{2}$ Since that time there has been considerable animal research on the effects of intermittent noise, some of which were attempts to determine the most appropriate ER for noncontinuous noise. Some of the earlier studies that appeared to support the ameliorative effects of intermittencies suffered from weaknesses, such as small populations and design limitations. Many experiments did show various benefits from intermittency, although they usually employed exposure conditions, such as pure tones or narrow bands of noise and levels of effective quiet between noise stimuli, which are atypical of workplace conditions. Findings from these studies can be helpful in determining the relative magnitude of the noise hazard. In other words, exposures that cause considerable amounts of $\mathrm{OHC}$ loss are destined to affect HTLs.
However, we now know that examination of TTS, PTS, and cell loss at the termination of exposure is no longer adequate to assess the hazard. Delayed recovery, particularly from impulse/impact exposures, is more problematic than previously thought as investigators began to assess cochlear damage for longer postexposure periods. We also know that the "toughening" phenomenon occurring with intermittent exposure does not protect the cochlea, and there appears to be a critical level at which hearing damage escalates.

Results from the more recent animal studies described herein point to the need for extra caution in the development of damage-risk criteria. In these experiments, using complex noise and large subject populations, intermittency failed to ameliorate cell loss or even PTS in several cases. It appears that the influence of short-duration transients, which are common in manufacturing and construction, need to be analyzed in a method that is more conservative than the $3-\mathrm{dB}$ rule.

Even though the chinchilla has long been accepted as an excellent model, the question of translation from animal models to the human is still under discussion. We need to determine the levels at which to expect the same effects in humans. Consequently, studies of workers in China who have had many years of exposure to the same job and little or no experience with hearing protectors have helped to fill the gap in demographic data. Plans are underway to conduct additional studies of these kinds of populations and to apply yet more sophisticated exposure metrics, such as additional kurtosis variants. This is a very important next step in the development of criteria for noise exposure, and these studies need to be conducted as quickly as possible before such populations are no longer available due to increasing efforts to implement hearing conservation programs. At the same time, these interventions should be readily encouraged.

It appears that strictly continuous noise in industry is the exception rather than the rule and that complex noise exposures, consisting of varying, intermittent, and interrupted noises, are more typical. It is clear that under certain conditions, complex or non-Gaussian noise is more damaging than Gaussian noise. The parameters of these conditions need to be carefully spelled out so that any metric may be modified in the appropriate ways. At this point, it appears 
that the 3-dB ER, modified by some value of kurtosis, holds the most promise for best predicting damage to the hearing mechanism. Such modifications may depend on noise exposure level, particularly the minimum levels of both background and kurtosis at which differences occur, frequency spectra of the background and impulse/impact noise, and other considerations, such as temporal spacing. Instruments such as the NIOSH noise meter should be very useful in these kinds of studies.

The synaptopathy investigations discussed previously lend considerable support for the need for a conservative approach to the development of any criteria to protect populations from hearing impairment. These studies have shown that damage to the auditory system is not adequately assessed by measures of auditory sensitivity or hair cell loss, and there is growing evidence that noise-induced damage to these synaptic ribbons is related to difficulties in understanding speech in background noise and the acceleration of presbycusis.

Although the 3-dB ER could be improved upon for conditions of complex noise exposure, especially for noise with high levels of kurtosis, any arguments for less protective ERs, such as the 5-dB ER, should no longer be considered. As research on synaptopathy progresses and the role of kurtosis in predicting hearing damage is further refined, we will need to reassess current criteria in terms of the REL, supplements to the $\mathrm{ER}$, and the administration of occupational hearing conservation programs. The research discussed in this report points in one direction-the hearing health of noise-exposed workers needs to be better protected.

\section{ACKNOWLEDGMENTS}

Preparing such a lengthy and detailed report requires not only time and effort, but the assistance of colleagues. Many thanks go to several people who reviewed drafts of the manuscript, particularly Wei Qiu, Sharon Kujawa, and Greg Flamme, for their thoughtful comments and for supplying excellent figures from their research. Thanks also to my reviewers at NIOSH: David Byrne, Chuck Kardous, Thais Morata, and especially to Bill Murphy, not only for his helpful review but for his invaluable assistance in redra- wing and editing the figures. Christa Themann's steady supply of journal articles was much appreciated, as was the patience and encouragement of Mark Stephenson, my project officer at NIOSH (contract \#254-2014-M-61063).

\section{REFERENCES}

1. U.S. Environmental Protection Agency (EPA). Noise in America: The Extent of the Noise Problem. Washington, DC: Office of Noise Abatement and Control; 1981. EPA Report 550/9-81-101

2. Suter AH. The Relationship of the Exchange Rate to Noise-Induced Hearing Loss. Cincinnati, OH: U.S. Department of Health and Human Services, National Institute for Occupational Safety and Health, Division of Standards Development and Technology Transfer; 1992. NTIS No. PB-93-118610

3. Passchier-Vermeer W. Noise induced hearing loss from exposure to intermittent and varying noise. In: Ward WD, ed. Proceedings of the International Congress on Noise as a Public Health Problem, Dubrovnik, Yugoslavia, May 13-18, 1973. Washington, DC: U.S. Environmental Protection Agency; 1973. EPA Report 550/973-008; pages 169-200

4. Kryter KD, Ward WD, Miller JD, Eldredge DH. Hazardous exposure to intermittent and steadystate noise. J Acoust Soc Am 1966;39(03):451-464

5. U.S. Environmental Protection Agency (EPA). Information on Levels of Environmental Noise Requisite to Protect Public Health and Welfare with an Adequate Margin of Safety. Washington, DC: Office of Noise Abatement and Control; 1974. Report 550/9-74-004

6. Flamme G, Murphy WJ. Brief high-level sounds. In: Meinke DK, Berger EH, eds. The Noise Manual, 6th ed. ( in press ). Fairfax, VA: American Industrial Hygiene Association Press

7. Hamernik RP, Hsueh KD. Impulse noise: some definitions, physical acoustics and other considerations. J Acoust Soc Am 1991;90(01):189-196

8. Henderson D, Hamernik RP. Impulse noise: critical review. J Acoust Soc Am 1986;80(02):569-584

9. Ahroon WA, Hamernik RP, Davis RI. Complex noise exposures: an energy analysis. J Acoust Soc Am 1993;93(02):997-1006

10. Lei SF, Ahroon WA, Hamernik RP. The application of frequency and time domain kurtosis to the assessment of hazardous noise exposures. J Acoust Soc Am 1994;96(03):1435-1444

11. Hamernik RP, Qiu W. Energy-independent factors influencing noise-induced hearing loss in the chinchilla model. J Acoust Soc Am 2001;110(06): 3163-3168 
12. International Organization for Standardization (ISO). Acoustics-Assessment of Occupational Noise Exposure for Hearing Conservation Purposes. 1st ed. Geneva, Switzerland: International Organization for Standardization; 1971(E). Reference No. ISO/R 1999

13. International Organization for Standardization (ISO). Acoustics-Determination of Occupational Noise Exposure and Estimation of Noise-Induced Hearing Impairment. Draft ed. Geneva, Switzerland: International Organization for Standardization; 1982. ISO DIS 1999

14. Glorig A, Ward WD, Nixon J. Damage risk criteria and noise-induced hearing loss. Arch Otolaryngol 1961;74:413-423

15. U.S. Department of Labor. Occupational Noise Exposure. Washington, DC: Bureau of Labor Standards; 1969. 34 Fed. Reg. 7948-7949

16. U.S. Environmental Protection Agency (EPA). Public Health and Welfare Criteria for Noise. Washington, DC: Office of Noise Abatement and Control; 1973. Report 550/9-73-002

17. Department of the Air Force. Hazardous Noise Exposure. Washington, DC: Medical Service, Office of the Surgeon General; 1956. Air Force Regulation 160-3

18. Department of the Air Force. Hazardous Noise Exposure. Washington, DC: Aerospace Medicine; 1973. Air Force Regulation 161-35

19. Department of the Air Force. Hazardous Noise Program. Washington, DC: Aerospace Medicine; 1993. Air Force Occupational Safety and Health Standard 48-19

20. International Organization for Standardization (ISO). Acoustics-Determination of Occupational Noise Exposure and Estimation of NoiseInduced Hearing Impairment. 2nd ed. Geneva, Switzerland: International Organization for Standardization; 1990(E). Reference No. ISO 1999

21. International Organization for Standardization (ISO). Acoustics-Estimation of Noise-Induced Hearing Loss. 3rd ed. Geneva, Switzerland: International Organization for Standardization; 2013. ISO/TC 43-Acoustics, 2013-10-01

22. American National Standards Institute/Acoustical Society of America (ANSI/ASA). Determination of Occupational Noise Exposure and Estimation of Noise-Induced Hearing Impairment. New York, NY: Acoustical Society of America; 1996. ANSI/ASA S3.44

23. Hétu R. Temporary threshold shift and the time pattern of noise exposure. Can Acoust 1982;10 (04):36-44

24. Harding GW, Bohne BA. Noise-induced haircell loss and total exposure energy: analysis of a large data set. J Acoust Soc Am 2004;115 (5 Pt 1):2207-2220
25. Holmgren G, Johnsson L, Kylin B, Linde O. Noise and hearing of a population of forest workers. In: Robinson DW, ed. Occupational Hearing Loss: Proceedings of a conference held at the National Physical Laboratory, Teddington, England, March 23-25, 1970. London: Academic Press; 1971. British Acoustical Society Special Volume Number 1

26. Johansson B, Kylin B, Reopstorff S. Evaluation of the hearing damage risk from intermittent noise according to the ISO recommendations. In: Ward WD, ed. Proceedings of the International Congress on Noise as a Public Health Problem, Dubrovnik, Yugoslavia, May 13-18, 1973. Washington, DC: U.S. Environmental Protection Agency; 1973. EPA Report 550/9-73-008; pages 201-210

27. Ward WD. The role of intermittence in PTS. J Acoust Soc Am 1991;90(01):164-169

28. Ward WD, Nelson DA. On the equal-energy hypothesis relative to damage-risk criteria in the chinchilla. In: Robinson DW, ed. Occupational Hearing Loss: Proceedings of a conference held at the National Physical Laboratory, Teddington, England, March 23-25, 1970. London: Academic Press; 1971. British Acoustical Society Special Volume Number 1

29. Ward WD, Turner CW. The total energy concept as a unifying approach to the prediction of noise trauma and its application to exposure criteria. In: Hamernik RP, Henderson D, Salvi R, eds. New Perspectives on Noise-Induced Hearing Loss. New York, NY: Raven Press; 1982

30. Ward WD, Turner CW, Fabry DA. The totalenergy and equal-energy principles in the chinchilla. Poster contribution to the Fourth International Congress on Noise as a Public Health Problem; June 1983; Turin, Italy

31. Bohne BA, Zahn SJ, Bozzay DG. Damage to the cochlea following interrupted exposure to low frequency noise. Ann Otol Rhinol Laryngol 1985;94(2 Pt 1):122-128

32. Bohne BA, Pearse MS. Cochlear damage from daily exposure to low-frequency noise. Unpublished manuscript. St. Louis, MO: Washington University Medical School, Department of Otolaryngology; 1982

33. Burns W, Robinson DW. Hearing and Noise in Industry. London, UK: Her Majesty's Stationery Office; 1970

34. Robinson DW, Shipton MS. Tables for the Estimations of Noise-Induced Hearing Loss. Teddington, England: National Physical Laboratory, Department of Trade and Industry; 1973. NPL Acoustics Report AC 61

35. Evans WA, Ming HY. Industrial noise-induced hearing loss in Hong Kong-a comparative study. Ann Occup Hyg 1982;25(01):63-80 
36. Institut National de Recherche et de Securite (INRS). Etude des risques auditifs auxquels sont soumis les salaries agricoles en exploitations forestieres et en scieries. INRS: Vandoeuvre-les-Nancy, France; 1978. Compte rendu d'etude No. 325 B

37. Ward WD. The "safe" workday noise dose. In: Proceedings from the Noise Shock \& Vibration Conference. Melbourne, Australia: Monash University; 1974:19-27

38. National Institute for Occupational Safety and Health (NIOSH). Survey of Hearing Loss in the Coal Mining Industry. Cincinnati, OH: U.S. Department of Health, Education, and Welfare, Public Health Service, Centers for Disease Control; 1976. Publication Number 76-172

39. National Institute for Occupational Safety and Health (NIOSH). Health Hazard Evaluation Report: Newburgh Fire Department, Newburgh, NY. Cincinnati, OH: U.S. Department of Health and Human Services, Public Health Service, Centers for Disease Control; 1982. HETA 81-059-1045

40. Passchier-Vermeer W. Steady-state and fluctuating noise: its effect on the hearing of people. In: Robinson DW, ed. Occupational Hearing Loss: Proceedings of a conference held at the National Physical Laboratory, Teddington, England, March 23-25, 1970. London: Academic Press; 1971. British Acoustical Society Special Volume Number 1

41. Shaw EAG. Occupational Noise Exposure and Noise-Induced Hearing Loss: Scientific Issues, Technical Arguments and Practical Recommendations. Report prepared for the Special Advisory Committee on the Ontario Noise Regulation. Ottawa, Ontario, Canada: National Research Council; 1985. APS 707; NRCC/CNRC Number 25051

42. Clark WW, Bohne BA, Boettcher FA. Effect of periodic rest on hearing loss and cochlear damage following exposure to noise. J Acoust Soc Am 1987;82(04):1253-1264

43. Sinex DG, Clark WW, Bohne BA. Effects of periodic rest on physiological measures of auditory sensitivity following exposure to noise. J Acoust Soc Am 1987;82(04):1265-1273

44. Fredelius L, Wersäll J. Hair cell damage after continuous and interrupted pure tone overstimulation: a scanning electron microscopic study in the guinea pig. Hear Res 1992;62(02):194-198

45. Pourbakht A, Yamasoba T. Cochlear damage caused by continuous and intermittent noise exposure. Hear Res 2003;178(1-2):70-78

46. Patuzzi R. Exponential onset and recovery of temporary threshold shift after loud sound: evidence for long-term inactivation of mechanoelectrical transduction channels. Hear Res 1998; 125(1-2):17-38
47. Lataye R, Campo P. Applicability of the L(eq) as a damage-risk criterion: an animal experiment. J Acoust Soc Am 1996;99(03):1621-1632

48. Bohne BA, Yohman L, Gruner MM. Cochlear damage following interrupted exposure to highfrequency noise. Hear Res 1987;29(2-3):251-264

49. Bohne BA, Harding GW. Degeneration in the cochlea after noise damage: primary versus secondary events. Am J Otol 2000;21(04):505-509

50. Subramaniam M, Henderson D, Spongr V. Effect of low-frequency "conditioning" on hearing loss from high-frequency exposure. J Acoust Soc Am 1993;93(02):952-956

51. Boettcher FA, Spongr VP, Salvi RJ. Physiological and histological changes associated with the reduction in threshold shift during interrupted noise exposure. Hear Res 1992;62(02):217-236

52. Hamernik RP, Ahroon WA. Interrupted noise exposures: threshold shift dynamics and permanent effects. J Acoust Soc Am 1998;103(06):3478-3488

53. Hamernik RP, Ahroon WA. Sound-induced priming of the chinchilla auditory system. Hear Res 1999;137(1-2):127-136

54. Ahroon WA, Hamernik RP. Noise-induced hearing loss in the noise-toughened auditory system. Hear Res 1999;129(1-2):101-110

55. Qiu W, Davis B, Hamernik RP. Hearing loss from interrupted, intermittent, and time varying Gaussian noise exposures: the applicability of the equal energy hypothesis. J Acoust Soc Am 2007; 121(03):1613-1620

56. Ward WD. Temporary threshold shift and damage-risk criteria for intermittent noise exposures. J Acoust Soc Am 1970;48(02):561-574

57. Luz GA, Hodge DC. Recovery from impulsenoise induced TTS in monkeys and men: a descriptive model. J Acoust Soc Am 1971; 49(06):1770-1777

58. Henderson D, Hamernik RP, Sitler RW. Audiometric and histological correlates of exposure to 1msec noise impulses in the chinchilla. J Acoust Soc Am 1974;56(04):1210-1221

59. Henderson D, Subramaniam M, Gratton MA, Saunders SS. Impact noise: the importance of level, duration, and repetition rate. J Acoust Soc Am 1991;89(03):1350-1357

60. Henderson D, Spongr V, Subramaniam M, Campo P. Anatomical effects of impact noise. Hear Res 1994;76(1-2):101-117

61. Dancer A, Grateau P, Cabanis A, Vaillant T, Lafont D. Delayed temporary threshold shift induced by impulse noises (weapon noises) in men. Audiology 1991;30(06):345-356

62. Trahiotis C. Application of animal data to the development of noise standards. In: Henderson D, Hamernik RP, Dosanjh DS, and Mills JH, eds. Effects of Noise on Hearing. New York, NY: Raven Press; 1976 
63. Eldredge DH, Miller JD, Mills JH, Bohne BA. Behavioral, physiological and anatomical studies of threshold shifts in animals. In: Ward WD, ed. Proceedings of the International Congress on Noise as a Public Health Problem, May 13-18, 1973; Dubrovnik, Yugoslavia. Washington, DC: U.S. Environmental Protection Agency; 1973. EPA Report 550/9-73-008; pages 237-256

64. Mills JH, Gengel RW, Watson CS, Miller JD. Temporary changes of the auditory system due to exposure to noise for one or two days. J Acoust Soc Am 1970;48(02):524-530

65. Mills JH, Osguthorpe JD, Burdick CK, Patterson JH, Mozo B. Temporary threshold shifts produced by exposure to low-frequency noises. J Acoust Soc Am 1983;73(03):918-923

66. Code of Federal Regulations (CFR). Occupational Noise Exposure. Washington, DC: U.S. Government Printing Office, Office of the Register. CFR; 1910.95

67. Ward WD, ed. Proposed Damage-Risk Criteria for Impulse Noise (Gunfire). Washington, DC: National Academies of Sciences-National Research Council: Committee on Hearing, Bioacoustics, and Biomechanics; 1968. Report of working group 57

68. Occupational Safety and Health Administration (OSHA). Occupational Noise Exposure: Proposed Requirements and Procedures. Washington, DC: U.S. Department of Labor; 1974. 39 Fed. Reg. 37773-37778

69. U.S. Department of Defense (DOD). Design Criteria Standard-Noise limits. Washington, DC: Department of Defense; 1997. MIL-STD1474D

70. U.S. Department of Defense (DOD). Design Criteria Standard-Noise limits. Washington, DC: Department of Defense; 2015. MIL-STD1474E

71. Price GR, Kalb JT. Insights into hazard from intense impulses from a mathematical model of the ear. J Acoust Soc Am 1991;90(01):219-227

72. Price GR. Predicting mechanical damage to the organ of Corti. Hear Res 2007;226(1-2):5-13

73. Price GR. Validation of the auditory hazard assessment algorithm for the human with impulse noise data. J Acoust Soc Am 2007;122(05): 2786-2802

74. Direction Technique des Armements Terrestres (DTAT). Recommendations on Evaluating the Possible Harmful Effects of Noise on Hearing. Bourges, France: Establissement Technique de Bourges; 1983. AT-83/27/28

75. Dancer A. $\mathrm{LA}_{\mathrm{eq}}$ 8hr: An effective DRC for weapon noises. Paper presented at: NIOSH/ NHCA Best Practices Workshop on Impulsive Noise and Its Effects on Hearing; April 7-8, 2003; Cincinnati, $\mathrm{OH}$
76. Hamernik RP, Patterson JH, Ahroon WA. Use of Animal Test Data in the Development of a Human Auditory Hazard Criterion for Impulse Noise. New York, NY: Auditory Research Laboratory, State University of New York; 1998. Final Report Part 1 and Part 2, submitted to Jaycor under subcontract agreement 950342

77. Murphy W, Kardous C. A Case for Using AWeighted Equivalent Energy as a Damage Risk Criterion. Cincinnati, OH: Department of Health and Human Services, National Institute for Occupational Safety and Health; 2012. EPHB Report No. 350-11a

78. Murphy W, Kahn A, Shaw P. An Analysis of the Blast Overpressure Study Data Comparing Three Exposure Criteria. Cincinnati, OH: Department of Health and Human Services, National Institute for Occupational Safety and Health; 2009. Report No. EPHB 309-05h

79. Murphy W, Kahn A, Shaw P. Analysis of Chinchilla Temporary and Permanent Threshold Shifts following Impulsive Noise Exposure. Cincinnati, OH: Department of Health and Human Services, National Institute for Occupational Safety and Health; 2010. Report No. EPHB 338-05c

80. Johnson DL. Blast Overpressure Studies with Animals and Man: A Walk-up Study. Albuquerque, NM: U.S. Army Aeromedical Research Laboratories; 1993. Final task report for U.S. Army Medical Research and Materiel Command. Technical report USAARL CR DAMD17-88C-8141

81. Johnson DL. Blast Overpressure Studies. Albuquerque, NM: U.S. Army Aeromedical Research Laboratories; 1997. Final task report for U.S. Army Medical Research and Materiel Command. Technical report USAARL CR DAMD17-93C-3101

82. Hamernik RP, Ahroon WA, Patterson JA Jr. Threshold recovery functions following impulse noise trauma. J Acoust Soc Am 1988;84(03): 941-950

83. Spoendlin H. Anatomical changes following various noise exposures. In: Henderson D, Hamernik RP, Dosanjh DS, Mills JH, eds. Effects of Noise on Hearing. New York, NY: Raven Press; 1976

84. Roberto M, Hamernik RP, Salvi RJ, Henderson $\mathrm{D}$, Milone R. Impact noise and the equal energy hypothesis. J Acoust Soc Am 1985;77(04): 1514-1520

85. Hamernik RP, Ahroon WA, Hsueh KD. The energy spectrum of an impulse: its relation to hearing loss. J Acoust Soc Am 1991;90(01): 197-204

86. Levine S, Hofstetter P, Zheng XY, Henderson D. Duration and peak level as co-factors in hearing 
loss from exposure to impact noise. Scand Audiol Suppl 1998;48:27-36

87. Gauger D, Berger EH. A new hearing protector rating: THE noise reduction statistic for use with A-weighting $\left(\mathrm{NRS}_{\mathrm{A}}\right)$. In: Report Prepared at the Request of the U.S. Environmental Protection Agency, version 2.5; April 29, 2004. E-A-R 0401/HP

88. American National Standards Institute/Acoustical Society of America (ANSI/ASA). Methods of Estimating Effective A-Weighted Sound Pressure Levels When Hearing Protectors Are Worn. New York, NY: Acoustical Society of America; 2007. ANSI/ASA 12.68

89. Kardous CA, Franks JR, Davis RR. NIOSH/ NHCA Best-Practices Workshop on impulsive noise. Noise Control Eng J 2005;53(02):53-60

90. Kardous CA, Murphy WJ. Noise control solutions for indoor firing ranges. Noise Control Eng J 2010;58(04):345-356

91. Gerges S, Sehrndt G, Parthey W. Noise sources. In: Goelzer B, Hansen CH, Sehrndt GA, eds. Occupational Exposure to Noise: Evaluation, Prevention, and Control. Dortmund, Germany: Federal Institute for Occupational Safety and Health, World Health Organization; 2001. WHO Special Report S 64

92. International Electrotechnical Commission (IEC). Electroacoustics-Sound level meters Part 1-Specifications. Geneva, Switzerland: International Electrotechnical Commission; 2002. International Standard IEC 61672-1

93. Kardous CA. Development and Validation Testing of an Impulse Noise Meter. Cincinnati, $\mathrm{OH}$ : Department of Health and Human Services, National Institute for Occupational Safety and Health; 2013. EPHB Report No. 350-11a

94. Dunn DE, Davis RR, Merry CJ, Franks JR. Hearing loss in the chinchilla from impact and continuous noise exposure. J Acoust Soc Am 1991; 90(4 Pt 1):1979-1985

95. Sulkowski WJ, Lipowczan A. Impulse noiseinduced hearing loss in drop forge operators and the energy concept. Noise Control Eng J 1982;18 (01):24-29

96. Thiery L, Meyer-Bisch C. Hearing loss due to partly impulsive industrial noise exposure at levels between 87 and $90 \mathrm{~dB}(\mathrm{~A})$. J Acoust Soc Am 1988; 84(02):651-659

97. Hamernik RP, Qiu W, Davis B. The effects of the amplitude distribution of equal energy exposures on noise-induced hearing loss: the kurtosis metric. J Acoust Soc Am 2003;114(01):386-395

98. Erdreich J. A distribution based definition of impulse noise. J Acoust Soc Am 1986;79(04): 990-998

99. Davis RI, Qiu W, Hamernik RP. Role of the kurtosis statistic in evaluating complex noise exposures for the protection of hearing. Ear Hear 2009;30(05):628-634

100. Hamernik RP, Ahroon WA, Davis RI, Lei SF. Hearing threshold shifts from repeated 6-h daily exposure to impact noise. J Acoust Soc Am 1994; 95(01):444-453

101. Hamernik RP, Qiu W, Davis B. Hearing loss from interrupted, intermittent, and time varying non-Gaussian noise exposure: the applicability of the equal energy hypothesis. J Acoust Soc Am 2007;122(04):2245-2254

102. Qiu W, Hamernik RP, Davis B. The kurtosis metric as an adjunct to energy in the prediction of trauma from continuous, nonGaussian noise exposures. J Acoust Soc Am 2006;120(06): 3901-3906

103. Qiu W, Hamernik RP, Davis RI. The value of a kurtosis metric in estimating the hazard to hearing of complex industrial noise exposures. J Acoust Soc Am 2013;133(05):2856-2866

104. Hamernik RP, Patterson JH, Salvi RJ. The effect of impulse intensity and the number of impulses on hearing and cochlear pathology in the chinchilla. J Acoust Soc Am 1987;81(04):1118-1129

105. Danielson R, Henderson D, Gratton MA, Bianchi L, Salvi R. The importance of "temporal pattern" in traumatic impulse noise exposures. J Acoust Soc Am 1991;90(01):209-218

106. Hamernik RP, Henderson D, Salvi R. Potential for interaction of low-level impulse and continuous noise. Wright Patterson Air Force Base, Dayton, OH: U.S. Air Force Aerospace Medical Research Laboratory; 1981. AFAMRL-TR-80-68

107. European Commission (EC). Council Directive of 12 May 1986 on the protection of workers from the risks related to exposure to noise at work. Council of European Communities; 1986. 86/ 188/EEC

108. European Commission (EC). Directive 2003/10/ EC of the European Parliament and of the Council on the minimum health and safety requirements regarding the exposure of workers to the risks arising from physical agents (noise). Official journal of the European Union: Seventeenth individual Directive within the meaning of Article 16(1) of Directive 89/391/EEC; 2003

109. Dobie RA, Clark WW. Exchange rates for intermittent and fluctuating occupational noise: a systematic review of studies of human permanent threshold shift. Ear Hear 2014;35(01):86-96

110. Suter AH. Letter to the editor: an alternative interpretation of issues surrounding the exchange rates Re: Dobie, R.A., \& Clark, W.W. (2014) Exchange Rates for Intermittent and Fluctuating Occupational Noise: A Systematic Review of Studies of Human Permanent Threshold Shift, Ear Hear, 35, 86-96. Ear Hear 2015;36(04): 485-487 
111. Voigt P, Godenhielm B, Ostlund E. Impulse noise-measurement and assessment of the risk of noise induced hearing loss. Scand Audiol Suppl 1980;12(01, Suppl 12):319-325

112. von Gierke HE, Robinson DW, Karmy SJ. Results of the Workshop on Impulse Noise and Auditory Hazard. Southampton, United Kingdom: University of Southampton, Institute of Sound and Vibration Research; 1981. ISVR Memorandum 618

113. Taylor W, Lempert B, Pelmear P, Hemstock I, Kershaw J. Noise levels and hearing thresholds in the drop forging industry. J Acoust Soc Am 1984; 76(03):807-819

114. Seixas N, Neitzel R, Sheppard L, Goldman B. Alternative metrics for noise exposure among construction workers. Ann Occup Hyg 2005; 49(06):493-502

115. Seixas NS, Neitzel R, Stover B, et al. 10-Year prospective study of noise exposure and hearing damage among construction workers. Occup Environ Med 2012;69(09):643-650

116. Zhao YM, Qiu W, Zeng L, et al. Application of the kurtosis statistic to the evaluation of the risk of hearing loss in workers exposed to high-level complex noise. Ear Hear 2010;31(04):527-532

117. Davis RI, Qiu W, Heyer NJ, et al. The use of the kurtosis metric in the evaluation of occupational hearing loss in workers in China: implications for hearing risk assessment. Noise Health 2012; 14(61):330-342

118. Xie HW, Qiu W, Heyer NJ, et al. The use of the kurtosis-adjusted cumulative noise exposure metric in evaluating the hearing loss risk for complex noise. Ear Hear 2016;37(03):312-323

119. Goley GS, Song WJ, Kim JH. Kurtosis corrected sound pressure level as a noise metric for risk assessment of occupational noises. J Acoust Soc Am 2011;129(03):1475-1481

120. National Institutes on Deafness and Other Communication Disorders/National Institutes of Health (NIDCD/NIH). Synaptopathy and Noise Induced Hearing Loss: Animal Studies and Implications for Human Hearing. Workshop summary and recommendations. Workshop May 4-5, 2015; Rockville, MD

121. Kujawa SG, Liberman MC. Acceleration of agerelated hearing loss by early noise exposure: evidence of a misspent youth. J Neurosci 2006; 26(07):2115-2123

122. Kujawa SG, Liberman MC. Adding insult to injury: cochlear nerve degeneration after "temporary" noise-induced hearing loss. J Neurosci 2009; 29(45):14077-14085

123. Kujawa SG, Liberman MC. Synaptopathy in the noise-exposed and aging cochlea: Primary neural degeneration in acquired sensorineural hearing loss. Hear Res 2015;330(Pt B):191-199
124. Lin HW, Furman AC, Kujawa SG, Liberman MC. Primary neural degeneration in the Guinea pig cochlea after reversible noise-induced threshold shift. J Assoc Res Otolaryngol 2011;12(05):605-616

125. Furman AC, Kujawa SG, Liberman MC. Noiseinduced cochlear neuropathy is selective for fibers with low spontaneous rates. J Neurophysiol 2013; 110(03):577-586

126. Fernandez KA, Jeffers PW, Lall K, Liberman MC, Kujawa SG. Aging after noise exposure: acceleration of cochlear synaptopathy in "recovered” ears. J Neurosci 2015;35(19):7509-7520

127. King PF. Psychogenic deafness. J Laryngol Otol 1954;68(09):623-635

128. Kopetzky SJ. Deafness, Tinnitus and Vertigo. New York, NY: Nelson; 1948

129. Plack CJ, Barker D, Prendergast G. Perceptual consequences of "hidden" hearing loss. Trends Hear 2014;18:1-11

130. Zhao F, Stephens D. A critical review of KingKopetzky syndrome: Hearing difficulties, but normal hearing? Audiol Med 2007;5(02):119-124

131. Moser T, Predoehl F, Starr A. Review of hair cell synapse defects in sensorineural hearing impairment. Otol Neurotol 2013;34(06):995-1004

132. Spoendlin H. Innervation densities of the cochlea. Acta Otolaryngol 1972;73(02):235-248

133. Zeng F-G. Uncovering hidden hearing loss. Hear J 2015;68(01):6

134. Schalk TB, Sachs MB. Nonlinearities in auditorynerve fiber responses to bandlimited noise. J Acoust Soc Am 1980;67(03):903-913

135. Costalupes JA, Young ED, Gibson DJ. Effects of continuous noise backgrounds on rate response of auditory nerve fibers in cat. J Neurophysiol 1984; 51(06):1326-1344

136. Gates GA, Schmid P, Kujawa SG, Nam B, D'Agostino R. Longitudinal threshold changes in older men with audiometric notches. Hear Res 2000;141(1-2):220-228

137. Rosenhall U. The influence of ageing on noiseinduced hearing loss. Noise Health 2003;5(20): 47-53

138. Schaette R, McAlpine D. Tinnitus with a normal audiogram: physiological evidence for hidden hearing loss and computational model. J Neurosci 2011;31(38):13452-13457

139. Roberts LE, Eggermont JJ, Caspary DM, Shore SE, Melcher JR, Kaltenbach JA. Ringing ears: the neuroscience of tinnitus. J Neurosci 2010;30(45): 14972-14979

140. Hickox AE, Liberman MC. Is noise-induced cochlear neuropathy key to the generation of hyperacusis or tinnitus? J Neurophysiol 2014;111(03):552-564

141. Bharadwaj HM, Masud S, Mehraei G, Verhulst $\mathrm{S}$, Shinn-Cunningham BG. Individual differences reveal correlates of hidden hearing deficits. J Neurosci 2015;35(05):2161-2172 
142. Makary CA, Shin J, Kujawa SG, Liberman MC, Merchant SN. Age-related primary cochlear neuronal degeneration in human temporal bones. J Assoc Res Otolaryngol 2011;12(06):711-717

143. Viana LM, O’Malley JT, Burgess BJ, et al. Cochlear neuropathy in human presbycusis: Confocal analysis of hidden hearing loss in post-mortem tissue. Hear Res 2015;327:78-88

144. Department of the Army. Noise and Conservation of Hearing. Washington, DC: Department of the Army; 1972. Technical Bulletin TB MED 251

145. Department of the Army. Hearing Conservation. Washington, DC: Department of the Army; 1980. Technical Bulletin TB MED 501
146. Department of the Army. Memorandum (Army Hearing Conservation Program Policy) of June 24, 1994, from Frederick J. Erdtmann, Deputy Director, Professional Services, Department of the Army, Office of the Surgeon General, Falls Church, VA; 1994. Memorandum SGPS-PSP (40-5)

147. Department of the Navy. Chapter 18, Hearing Conservation and Noise Abatement. Washington, DC: Department of the Navy; 1994. OPNAVINST 5100.23D

148. Department of the Navy. Navy Medical Department Hearing Conservation Program Procedures. Washington, DC: Department of the Navy; 2008. TM 6260.51.99-2 